\title{
The Measurement of the Wear of Tie Rod End Components
}

\author{
Marek Wozniak ${ }^{1}$ - Adam Rylski ${ }^{2}$ - Krzysztof Siczek ${ }^{1, *}$ \\ ${ }^{1}$ Lodz University of Technology, Department of Vehicles and Fundamentals of Machine Design, Poland \\ ${ }^{2}$ Lodz University of Technology, Institute of Materials Science and Engineering, Poland
}

This study aimed to determine the wear intensity of the bearing mating with the ball stud in the tie rod end. The course of the vehicle driving during the period between repairs of the steering assembly was assumed. The modelled scheme of cornering was assumed to be close to the real one. The model of steering mechanism allowing determination of the load of the stud of the tie rod end as a function of the steering angle was elaborated and presented. The model of the ball stud was realized and described. The values of wear intensity for components were calculated and presented.

Keywords: tie rod end, wear degree, finite element method, steering mechanism system

\section{Highlights}

- Wear of the steel ball end of a stud was much lower than that of its polyoxymethylene (POM) bearing in the case of the tie rod end.

- For the POM bearing of the stud, the wear intensity factor $k$ was equal to $1.38 \cdot 10^{-19} \mathrm{~m}^{4} \cdot \mathrm{N}^{-2}$ and corresponded to the linear wear intensity $I_{h}$ equal to $5.9 \cdot 10^{-9}$.

- The linear wear intensity $I_{h}$ for the POM bearing can vary in a wide range depending on the contact pressure, sliding speed, temperature, humidity, and the operating and lubricating conditions for the tie rod end assembly.

- $\quad$ The averaged values of contact pressure between the steel ball end and its POM bearing almost linearly increased with the force F loading the steering tie rod for values of such a force below $500 \mathrm{~N}$.

\section{INTRODUCTION}

A vehicle suspension is defined as a group of elastic elements and rods connecting the axes or the individual wheels of a car with a frame or directly with a vehicle body. The purpose of suspension is to diminish shocks coming from road unevenness, assuring maximum comfort and protection of transported objects against shocks and harmful vibrations. Securing the vehicle from too strong shocks also has a significant influence on the durability of various mechanisms. One of the main components of the vehicle suspension is a tie rod end. The task of the tie rod end is to enable the wheels to turn while maintaining the vehicle in the straight line.

Mondragon-Parra et al. [1] asserted that the driveline and chassis components account for about 2 $\%$ of the total mechanical losses in passenger vehicles.

The repair methods for various components of the suspension system, including tie rods ends, were discussed in [2].

Chavan and Patnaik [3] stated that the tie rod may fail due to varying forces and bumping of vehicle during steering. The forces from the steering are also crucial during the static condition of the vehicle. Excessive vibration and buckling of tie rod may lead to structural failure. The authors assessed buckling strength and compared the buckling performance of tie rods for different materials. Using finite element models of the tie rod, they obtained stiffness and stress distributions in each component of the tie rod.

Falah et al. [4] described the vehicle tie rod as tangentially loaded because of the vertical, lateral, and horizontal forces acting on the suspension system when the vehicle operates in long-term conditions. The tie rod material does not exceed the elastic limit, and these varying loading effects directly influence the performance of the car linkages like the tie rods. Many conventional vehicles operate with a steering system known as rack and pinion, which incorporates tie rods.

Guiggiani [5] stated that the tie rods are slender structural elements that can be used as tie-carrying tensile loads. Tie rods are part of the steering mechanism, which operates under both tensile and compressive stress. The ratio of a typical tie rod length in the cross-section is very large, and it could buckle under the influence of compressive load.

Manik et al. [6] concluded that the working strength of a tie rod is the product of the allowable working stress and the minimum cross-sectional area. Each end of a steering rack is joined to the tie rod. The pinion rotates over the slotted rack. Its function is pushing and pulling the front wheels as the steering turns either to the left or the right side of the car. The presented results showed that the distribution of deformation and stress does not exceed the yield strength value and that there are neither damages nor 
failure of the tie rod. However, the correctness and accuracy of calculations results are dependent on selected modelling parameters.

Kim et al. [7] wrote about forging aluminium alloy tie rod ends for the vehicle steering systems. In the casting experiment, the effects of additives, Ti, B, $\mathrm{Zr}$, Sr, and $\mathrm{Mg}$, improve the mechanical properties. Finite element analysis was performed to define an optimal configuration of the cast preform. It was observed that the highest hardness was obtained for added $0.2 \% \mathrm{Mg}$. They used the finite element model to determine an optimal configuration of the cast preform.

Essienubong et al. [8] determined that vehicle tie rod should resist the vertical, lateral, and horizontal forces acting on the suspension system when the vehicle operates in long-term conditions. The tie rod material does not exceed the elastic limit. The tie rod can be made of nickel alloys, titanium alloy, aluminium alloy, and low alloy steel. The tie rod requires a high value of modulus of elasticity for stiffness, high fracture toughness, and resistance against wear and fatigue.

Aravindaraj et al. [9] reported that a tractor connecting tie rod failed due to the overload applications.

Natrayan et al. [10] studied old tie rod design and materials applied in agriculture and then analysed a modified design with various stresses and deformation characteristics under critical loading conditions using ANSYS software.

Also, Ozsoy and Pehlivan [11] conducted the structural analysis of a tie rod end part for a vantype vehicle using the finite element model of the body, the joint, and the bearing. The analyses for the joint assembly were carried out for various tie-end orientations. They studied the stress variations and deformation characteristics of each component for various operational loading conditions.

Patil et al. [12] numerically determined the natural frequency and the static stress of the tie rod end and the rod arm for a specific vehicle. They modelled the whole mechanism as a single part and found that it could operate safely.

Senniappan et al. [13] studied a steering tie rod arm of a heavy commercial vehicle. Through computer-aided engineering (CAE) analysis, the authors predicted the life of the initial design proposal of the steering tie rod arm and compared it with the actual component test life.

Using the failure modes, effects, and criticality analysis (FMECA), Ćatić et al. [14] carried out a criticality analysis of failure modes of a light commercial vehicle's steering tie rod joint elements.

Interestingly, using the material selection and the optimization technique, Park et al. [15] developed a lightweight outer tie rod for an electric vehicle. They utilized aluminium alloy A16082M and improved the tie rod structural shape using metamodel-based optimization.

The tie rod end consists of a ball joint. During vehicle cornering, the wear of mating surfaces of the tie rod end components, such as the ball end of the cotter pin and its bearing, occurs. The wear in tribological pairs can be modelled using various models [16] to [19].

Zwierzycki [19] proposed a general model of wear in tribological pair, in which the volumetric wear rate $w_{z}$ is proportional to the contact area $S$, sliding velocity $v$ and linear wear intensity wear intensity $I_{h}$. The latter is affected by two parameters: factor $k$ and pressure exponent $x$. The latter varies usually in a range of $<1,2>$ [19] and [20]. Such two parameters are functions of material properties, geometrical characteristics of surfaces, etc. An experimental determination of these parameters is described in [21]. Some values of parameter $k$ for various tribological contacts were given in [20] and [22].

The similar linear wear intensity wear intensity $I_{h}$ with exponent $x$ equal to 1 was utilized by Burdzik et al. [23] during studies on the tribological behaviour of contact between samples made of cast iron conducted on the pin-on-disc tribometer under dry conditions and under lubrication with engine oil.

The linear dependence of the linear wear intensity $I_{h}$ on the average pressure to friction force was also reported in [24].

This article aims to obtain the volumetric wear of components for the tie rod end and the parameters of assumed wear model of them under specific history (conditions) of the cornering process. During analysis, different models of the tie rod end and steering mechanism were used.

The authors managed to estimate experimentally the value of the wear intensity factor $k$ for the POM bearing of the stud, which has not been presented in the literature thus far. This factor corresponded to the linear wear intensity $I_{h}$, rarely used in the literature to quantify the wear process in the joints.

The effect of lubrication occurrence in contact zone on the load sharing between the one carried by direct contact of rough asperities and the one countered by hydrodynamic effect from the grease microclines between them. The effect of squeezing the 
grease film on the pressure in the grease layer between the stud ball end and its bearing was also analysed.

\section{TIE ROD END}

The ball joint of the tie rod end is a movable connection enabling a rotationally oscillating movement of one of the connected components relative to the other. The instantaneous axis of the wheel rotation is strongly affected by the cotter pin axis. Additionally, it enables angular deflection and transmits shearing and longitudinal forces. Since the ball joints perform a rotationally oscillating movement, they are lubricated with different greases [25]. The main components of the tie rod end are presented in Fig. 1, inspired by [25], and [26].

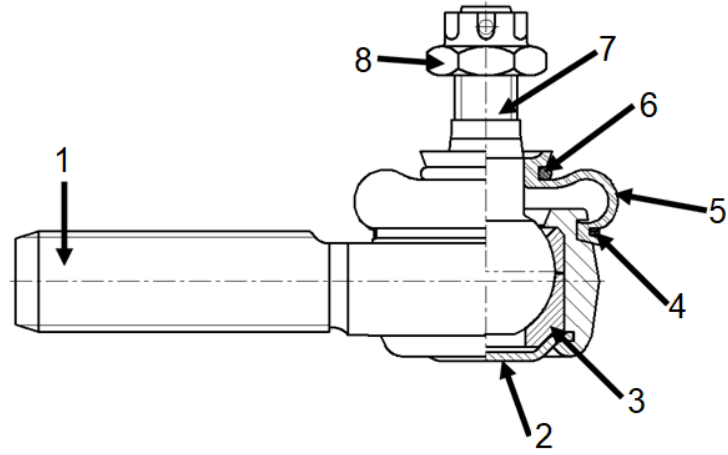

Fig. 1. Components of the tie rod end; 1 body, 2 lower cup, 3 lower part of bearing, 4 lower ring, 5 dust boot and dust boot skirt, 6 upper ring, 7 ball stud, 8 castle nut with cotter pin, inspired by [25], and [26]

\section{THE FLOW CHART OF CALCULATIONS}

The realization of this article's main aim needs to assume a wear model in the contact zone between mating components of the tie rod end and to identify its parameters. This needs the knowledge of parameters influencing such wear, including sliding speed mating components of the tie rod end, their geometry, and loading at the distance for which such wear occurs.

The distance and sliding velocity are functions of the number and values of steering angles of vehicle wheels, and they depend on courses of vehicle velocity and millage resulted from the vehicle driving history. Because driving history has not been registered due to costs of the appropriate equipment, it can only be estimated, as described in Chapter 3.

The geometry of the contact zone between mating components, namely cotter pin and main POM bearing (Fig. 1), is the function of outer radius $D_{1} / 2$ of the ball of the cotter pin and inner radius $D_{2} / 2$ and shape of the main POM bearing. The geometry of the contact zone also depends on an applied force $F_{L}$, so the necessary physical and mathematical model has been elaborated and described in a further chapter.

The load of the contact zone is a function of torques due to vertical, lateral, and tractive forces loading the wheels of the vehicle and kinematic relationships between components of the vehicle steering mechanism. Torques $M_{V}$ due vertical, $M_{L}$ due lateral and $M_{T}$ due tractive forces vary mainly with steering angle $\delta_{f}$ and average vehicle velocity $v_{\text {aver }}$ during turning. Kinematic relationships vary with steering angle $\delta_{f}$. The load has been estimated using the model of vehicle cornering and the modelled trajectory of the cotter pin against the main POM bearing (Fig. 1).

The information obtained from calculations is complex and of a semi-iterative nature, particularly in the case of the determination of the lateral force $F_{L}$. A simplified flow chart of calculations is presented in Table 1.

\section{THE COURSE OF VEHICLE DRIVING}

Hegedüs et al. [27] reported that the planning of proper road vehicle trajectories became a critical and complex issue due to the enhanced interest in the automation of road transportation. During such a planning, it is necessary to consider the nonholonomic dynamics of wheeled vehicles. Only nonlinear optimizationbased trajectory planners are able to reach valuable results, but at the expense of enhanced computational needs sometimes up to not acceptable levels. Such problems can be fully or only partly resolved using a hybrid approach based on artificial neural networks (ANNs). Similar problems can occur when recreating the trajectories of the movement of various cars that, for example, were involved in road incidents [28] and [29], during the preparation of trainers for drivers of special or high-speed vehicles or the elaboration of driving simulators [30] to [32].

Lefèvre et al. [33] reviewed various methods for motion prediction and risk assessment for intelligent vehicles. It was emphasized that the choice of a risk assessment method depended on the selected motion model.

According to [34], the trajectory of a vehicle strongly depends on the interactions between the vehicle, the driving behaviour, and the road environment. The knowledge of the relationship between the trajectory and road geometry facilitates the identification of high-risk driving behaviours. 
Table 1. The simplified flowing chart of calculations

\begin{tabular}{|c|c|c|c|c|}
\hline Input & Input parameters & Model & Output parameters & Output \\
\hline & & START & & 1 \\
\hline \multirow{2}{*}{1} & \multirow{2}{*}{$\begin{array}{l}\text { Time history of } j^{\text {th }} \text { vehicle turnings, } \\
\text { when } j=1, \ldots, N\end{array}$} & \multirow{2}{*}{$\begin{array}{c}\text { Driver decision model (course of driving) } \\
\text { Chapter } 4\end{array}$} & $v_{\text {aver }}(j), \alpha_{\max }(j), R(j)$ & 2 \\
\hline & & & Turning number $j$ & 3 \\
\hline 2 & $v_{\text {aver }}(j), \alpha_{\max }(j), R(j)$ & Cornering scheme Chapter 5 & $t_{u}(j), v_{b}(j)$ & 4 \\
\hline Measured & $D_{1}, \Delta D_{1}, D_{2}, \Delta D_{2}$ & Wear calculation Chapter 8 & Volumetric wear $W_{1}, W_{2}$ & 5 \\
\hline 3 & Turning number $j$ & \multirow[b]{2}{*}{ Wear distance calculation Chapter 8} & \multirow{2}{*}{$\begin{array}{c}\text { Wear distance } \\
l_{z}=\sum_{j=1}^{M} v_{b}(j) \cdot t_{u}(j)\end{array}$} & \multirow[b]{2}{*}{6} \\
\hline 4 & $t_{u}(j), v_{b}(j)$ & & & \\
\hline Measured & $D_{1}, D_{2}$ & \multirow{3}{*}{ FEM model of the ball joint Chapter 8} & \multirow{3}{*}{ Contact pressure $p$} & \multirow{3}{*}{7} \\
\hline Assumed & Material parameters $E_{1}, v_{1}, E_{2}, v_{2}$ & & & \\
\hline 9 & Load of steering $\operatorname{rod} F$ & & & \\
\hline Assumed & $\begin{array}{c}F_{L 0}=m v_{\text {aver }}^{2}(j) / R(j), \\
a_{0}, a_{1}, a_{2}, a_{3}, a_{4}, a_{6}, a_{7}, a_{17}\end{array}$ & Magic Tire Formula Chapter 9 & $\alpha_{f 0}, \alpha_{r 0}$ & 8 \\
\hline Assumed & $H_{c}, R_{c}, h_{c} \cdot d_{c}, m, f_{t}, \rho, C_{x}, A, s, \alpha_{c}, \lambda, v_{c}, g$ & \multirow{5}{*}{$\begin{array}{c}\text { Model of steering mechanisms } \\
M_{V} \text { torque due vertical force, } M_{L} \text { torque due } \\
\text { lateral force, } M_{T} \text { torque due tractive force } \\
\text { Chapter } 6\end{array}$} & \multirow{5}{*}{ Load of steering rod $F$} & \multirow{5}{*}{9} \\
\hline Measured & $F_{z}$ & & & \\
\hline 2 & Turning speed $v_{\text {aver }}(j)$ & & & \\
\hline 10 & Steering angle $\delta_{f}$ & & & \\
\hline 13 & Lateral force $F_{L}$ & & & \\
\hline 8 & $\alpha_{f 0}, \alpha_{r 0}$ & \multirow{3}{*}{$\begin{array}{l}\text { Steering angle calculation } \\
\text { Chapter } 9\end{array}$} & \multirow{3}{*}{ Steering angle $\delta_{f}$} & \multirow{3}{*}{10} \\
\hline Measured & Vertical force $F_{z}$ & & & \\
\hline 2 & $R(j)$ & & & \\
\hline 10 & Steering angle $\delta_{f}$ & \multirow{3}{*}{ Model of cornering vehicle Chapter 9} & \multirow{3}{*}{$\omega, \beta$} & \multirow{3}{*}{11} \\
\hline Assumed & $a_{r}, a_{f}, t_{r}, t_{f}, I_{z}$ & & & \\
\hline 2 & Turning speed $v_{\text {aver }}(j)$ & & & \\
\hline 11 & $\beta$ & Slip angle iteration Chapter 9 & $\alpha_{f}, \alpha_{r}$ & 12 \\
\hline Assumed & $a_{0}, a_{1}, a_{2}, a_{3}, a_{4}, a_{6}, a_{7}, a_{17}$ & \multirow{2}{*}{ Magic Tire Formula Chapter 9} & \multirow{2}{*}{ Lateral force $F_{L}$} & \multirow{2}{*}{13} \\
\hline 12 & $\alpha_{f}, \alpha_{r}$ & & & \\
\hline 5 & Volumetric wear $W_{1}, W_{2}$ & \multirow{4}{*}{ Volumetric wear model Chapter 8} & \multirow{4}{*}{$\begin{array}{l}\text { Volumetric wear model } \\
\text { parameter } k_{1}, k_{2}\end{array}$} & \multirow{4}{*}{14} \\
\hline 6 & Wear distance $l_{z}=\sum_{j=1}^{M} v_{b}(j) \cdot t_{u}(j)$ & & & \\
\hline 7 & Contact pressure $p$ & & & \\
\hline 9 & Load of steering rod $F$ & & & \\
\hline 14 & & FINISH & & \\
\hline
\end{tabular}

Using the field driving experiments performed on a certain number of selected highways, $\mathrm{Xu}$ et al. [34] studied the trajectories passenger cars took on twolane mountain roads and determined the track patterns and their relevant risks.

The new area for studies on trajectory control relates to various mobile robots [35] and unmanned vehicles [36] to [40].

According to [35], the steering control of mobile robot trajectory can relate to a wide range of turning issues: from highway driving, with negligible turning for prolonged distances, up to steering for battlefield robots, requiring agile turning. The author reviewed different steering schemes that are used for robotic vehicles and battlefield robot vehicles. Skid steering and four-wheel steering were analysed.
Li et al. [41] explained that overtaking is a complex and challenging manoeuvre for road vehicles and the autonomous control of the vehicle during such a manoeuvre can enhance vehicle safety. Fourwheel independent steering (4WIS) and four-wheel independent driving (4WID) for the autonomous electric vehicles provide redundant control, enabling better control.

Zheng and Yang [42] proposed a trajectory tracking strategy based on the hierarchical control method for the 4WIS/4WID electric vehicle with the independently controlled rotation angle and driving torque of each wheel.

In the present study, researchers attempted to recreate the trajectory of vehicle motion based on data obtained from an interview with the driver driving 
his car in a relatively repeatable manner on similar routes over a known time. In the analysis, the driver with his Ford Mondeo, who has driven each working day from his house to the job and returned from it, was considered. Doing so, he drives $60 \mathrm{~km}$ per day and $15,600 \mathrm{~km}$ per year. Additionally, about 5 to 6 weekends per year he made longer journeys of $250 \mathrm{~km}$ to $300 \mathrm{~km}$. This gives $1250 \mathrm{~km}$ to $1800 \mathrm{~km}$ per year. After six years the total millage was equal to 93,600 $+(7,500$ to 10,800$) \mathrm{km}$. During this $93,600 \mathrm{~km}$, the road distances were practically repeatable, and they were driven with an average speed $50 \pm 10 \mathrm{~km} / \mathrm{h}$. The route required the driver to make 20 major turns of about $90 \mathrm{deg}$. Their assumed radius was $20 \mathrm{~m}$. This yielded 5500 such turns after six years. Additionally, he had to make about 30 smaller turns about $40 \mathrm{deg}$ due to overtaking or bypassing other road users. Their assumed radius was $50 \mathrm{~m}$. This yielded 8250 such turns for 6 years. He had also to make small turns (100 to 500 depending on the seasons of the year - averaged 300) of about 1 degree because of the existing ruts on the roads. Their assumed radius was smaller than $120 \mathrm{~m}$. This yielded 82,500 such turns after six years. During 7,500 km to $10,800 \mathrm{~km}$ of motion, the changes of speed were more dynamic. It was assumed that the average speed was about $80 \pm 20 \mathrm{kph}$. Due to the lack of data, it was assumed that the driver made proportionally fewer big turns, namely 440 to 630 turns with the radius of $20 \mathrm{~m}$ to $500 \mathrm{~m}$, averaged to $275 \mathrm{~m}$ and an angle of 90 degrees, about 660 to 950 smaller turns with the radius equal $50 \mathrm{~m}$ and angle 40 degrees and about 6,600 to 9,500 small turns with the radius $R$ less than $120 \mathrm{~m}$ and angle of fewer than 1 degree. It was assumed that the car was moving at the maximum speed allowed without slip during cornering (below $14 \mathrm{~m} \cdot \mathrm{s}^{-1}$ ).

\section{THE SCHEME OF CORNERING}

Jiang et al. [43] proposed a human-like trapezoidal steering angle model to quantitate the relationship between objective road factors and steering wheel angles generated by human drivers. They elaborated the idealized curve described by the straight curve length, the radius of curve $R$, and curve subtended angle $\alpha$, constituting three consecutive sections: straight, circular curve, and straight. The driving speed on the ideal curve was assumed to be constant. As the steering positions of human drivers disagreed with the varying geometrical position of the curve, a series of feature distances replicating the actual human steering positions on the curve was introduced in the proposed steering angle model.
In this study, the simpler scheme of each $j^{\text {th }}$ cornering was assumed as follows. During the first one-fifth of the turn length $l_{\max }(j)$, the driver turns the steering wheels to the needed angle value, namely $a_{\max }(j)$ equal to 1,40 or 90 degrees, respectively. The next three-fifths of the turn length he keeps the steering wheels with the same constant angle value. During the last one-fifth of the turn length, the driver turns the steering wheels back to the initial position. Such an algorithm was illustrated in Fig. 2. The time of the $j^{\text {th }}$ cornering can be estimated from Eq. (1).

$$
t_{u}(j) \approx \frac{l_{\max }(j)}{v_{\text {aver }}(j)}=\frac{\alpha_{\max }(j) \cdot R(j)}{v_{\text {aver }}(j)},
$$

where $j=1, \ldots \mathrm{M}$ is number of cornering, $M$ total number of cornering made by the driver, $R(j)$ the radius of the $j^{\text {th }}$ cornering $[\mathrm{m}]$, and $v_{\text {aver }}(j)$ average speed of vehicle during the $j^{\text {th }}$ cornering $\left[\mathrm{m} \cdot \mathrm{s}^{-1}\right]$.

The time of turning the steering wheel forward and back is equal to $0.4 t$.

An average speed of the bearing relative to the ball stud during the $j^{\text {th }}$ cornering was estimated from Eq. (2).

$$
v_{b}(j) \approx \frac{2 \cdot \alpha_{\max }(j) \cdot d_{\text {ball }}}{0.4 \cdot t_{u}(j)},
$$

where $d_{\text {ball }}$ is the average diameter of spherical surface of the ball stud [m].

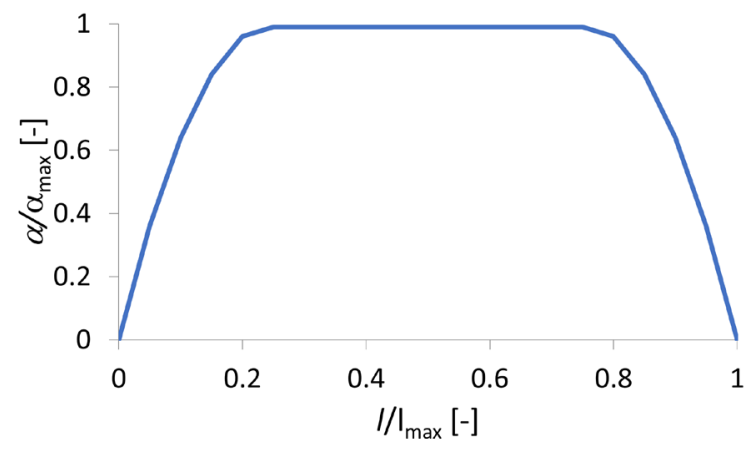

Fig. 2. The scheme of cornering

\section{THE MODEL OF STEERING MECHANISM}

The kinematic scheme of the steering mechanism is presented in Fig. 3. The steering angle $\delta$ is the independent variable. The following parameters are constants: $H_{c}=160 \mathrm{~mm}, \alpha_{c}=42^{\circ}, R_{c}=120 \mathrm{~mm}, h_{c}=$ $200 \mathrm{~mm}$, and $d_{c}=250 \mathrm{~mm}$.

The force $F$ loading the steering rod is estimated from Eq. (3). 


$$
F=\frac{M_{V}+M_{L}+M_{T}}{q \cdot \cos \left(\beta_{C}+\varepsilon+\delta\right)} .
$$

The angle $\varepsilon$ is calculated from Eq. (4).

$$
\varepsilon=\sin ^{-1}\left(h_{c} \cdot \sin \left(\alpha_{c}\right) / q\right) .
$$

The constant distance $q$ is calculated from Eq. (5).

$$
q=\sqrt{R_{c}^{2}+h_{c}^{2}-2 R_{c} h_{c} \cos \left(\alpha_{c}\right)} .
$$

The angle $\beta$ is calculated from Eq. (6).

$$
\beta_{c}=\sin ^{-1}\left(\frac{H_{c}-q \times \sin (\varepsilon+\delta)}{d_{c}}\right) .
$$

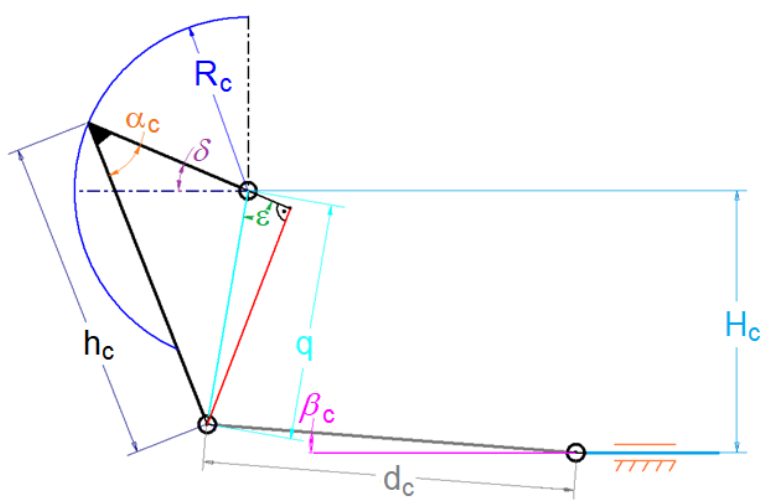

Fig. 3. The kinematic scheme of the steering mechanism

Three factors affecting the steering force are vertical load, lateral force, and tractive force. Each of these conditions produces a torque acting on the steering axis, and the torque is balanced through the steering rack. The total torque about the steering axis is a summation of the individual torques.

The torque resulting from the vertical load was calculated from Eq. (7).

$$
\begin{aligned}
M_{V}= & -\left(F_{z l}+F_{z r}\right) \cdot s \cdot \sin (\lambda) \cdot \sin (\delta) \\
& +\left(F_{z l}+F_{z r}\right) \cdot s \cdot \sin \left(v_{c}\right) \cdot \cos (\delta),
\end{aligned}
$$

where (values readout from catalogue): $F_{z l}=4790 \mathrm{~N}$ is vertical load for left wheel, $F_{z r}=3110 \mathrm{~N}$ vertical load for right wheel, $s=-0.006 \mathrm{~m}$ lateral offset at the ground, $\lambda=7^{\circ}$ lateral inclination angle (estimated), $\delta$ steer angle $\left[{ }^{\circ}\right]$, and $v_{c}=3.32 \pm 1^{\circ}$ caster angle.

The torque resulting from the lateral force was calculated from Eqs. (8) and (9).

$$
\begin{gathered}
M_{L}=-\left(F_{y l}+F_{y r}\right) \cdot r \cdot \tan (v), \\
F_{y l}=F_{y r}=C_{f} / 4,
\end{gathered}
$$

where $C_{f}$ is cornering force $[\mathrm{N}], F_{y l}$ lateral force for left wheel $[\mathrm{N}], F_{y r}$ lateral force for right wheel $[\mathrm{N}]$, and $r=0.32 \mathrm{~m}$ tire radius.

The torque due to tractive force, calculated from Eq. (10).

$$
M_{T}=\left(F_{x l}+F_{x r}\right) \cdot s,
$$

where $F_{x l}$ is tractive force for left wheel [N], and $F_{x r}$ tractive force for right wheel [N].

The cornering force $C_{f}$ was estimated from Eq. (11).

$$
C_{f}=m v_{\text {aver }}^{2}(j) / R(j) .
$$

The tractive force $F_{x}$ was estimated from Eq. (12).

$$
F_{x}=m g f_{t}+0.5 \rho C_{x} A v_{\text {aver }}^{2},
$$

where $m=1580 \mathrm{~kg}$ is mass of the vehicle, $f_{t}=0.01$ rolling resistance coefficient, $\rho=1.29 \mathrm{~kg} \cdot \mathrm{m}^{-3}$ air density, $C_{x}=0.31$ drag coefficient, and $A=0.84 \cdot H_{c a r} \cdot W_{c a r}=2.055 \mathrm{~m}^{2}$ reference frontal area.

\section{OPERATIONAL CONDITIONS FOR THE ANALYSED STUD OF THE STEERING ROD}

The ball joint can be made of AISI-SAE 5140 steel, usually heat treated by quenching and tempering with the resulted microstructure of tempered martensite with acicular ferrite [44]. Such heat treatment resulted in higher material toughness [45] and [46], as cited in Ossa et al. [44], lower fracture toughness, and mechanical strength decreasing element durability, and local reduction on the material hardness lowering the fatigue endurance limit.

According to Murakami [47], as cited in Ossa et al. [44], the uniaxial fatigue strength $\sigma_{f}$ depends on the Vickers hardness $H_{v}$ as Eq. (13).

$$
\sigma_{f}=1.6 H_{v} \pm 0.1 H_{v} .
$$

The calculated Vickers hardness of the failed element was of $353 H_{v}$. Using Eq. (13), the uniaxial fatigue strength of the material is $565 \pm 35.3 \mathrm{MPa}$ level. According to Alsaran et al. [48], as cited in Ossa et al. [44], the heat treatment of AISI-SAE 5140 steel used for suspension system ball joints resulted in a fatigue endurance limit of $416 \mathrm{MPa}$. As Alsaran's endurance limit does not exceed the value obtained from Eq. (13), this value is then used as the bulk fatigue endurance limit of the analysed ball joint element. The endurance limit calculated from Eq. 13 for the acicular ferrite approximates $326 \pm 20.4 \mathrm{MPa}$. Loading for the stud of steering rod can approach up to $500 \mathrm{~N}$ [49], $1540 \mathrm{~N}$ [50] or even $2000 \mathrm{~N}$ [11]. 
The operational conditions of the analysed stud of the steering rod were highly affected by the lubrication conditions in the contact zone between the stud ball end and its insert. The lithium greases in pure form and with various additives are often used for the lubrication of ball joints in car suspensions.

Miettinen and Andersson [51] found that the lubrication significantly affected the acoustic characteristics rolling bearings.

Sharma et al. [52] elaborated a theoretical model for studies of the effects of operating parameters on the energy of acoustic emission (AE) generated in rolling element bearing. The model was based on the asperities-level interaction between the mating surfaces of bearing components using the Hertzian contact approach, statistical concepts, contact load distribution during the load zone, and lubrication effects.

Patil et al. [53] examined the effects of Hertzian deformations between the mating bodies, elastohydrodynamic lubrication (EHL), and elastic asperity interactions of rough surfaces on combined acoustic and dynamic characteristics of a ball bearing.

Wang et al. [54] developed the dynamic models allowing considering the effects of dynamic contact forces, EHL rolling friction torque, centrifugal forces, elastic hysteresis, differential sliding friction torques on the ball motion state, and slipping in the rolling bearings.

Liu et al. [55] proposed an interesting dynamic model of angular contact ball bearing (ACBB), which enabled considering the effects of elastic hysteresis, differential sliding friction torques, and EHL rolling on the ball motion state.

Masjedi and Khonsari [56] related the shear friction force between the raceways and ball from:

- the contact force and the relative sliding speed between the raceways and ball, and the ellipse contact area dimensions,

- features of asperities, including their friction coefficient of asperities, their load ratio, and their ultimate shear stress coefficient,

- features of the oil film, including the pressure sustained by it, its average viscosity, its ultimate shear stress, and the central oil film thickness.

Tong and Hong [57] elaborated a friction torque model of ACBB, including the shear friction force and the ball friction force depending on the elastic hysteresis, EHL rolling, and differential sliding friction torques.

Marques et al. [58] determined that in mechanical joints, a static friction model with elimination of the discontinuity at zero velocity was usually a good choice. For such joints operating under highly variable normal loads, a dynamic friction model was required. Fortunately, apart from participation in rallies, the dynamics of loads on tie rod ends in vehicles driving mainly on the most frequently used roads is not so large.

\section{WEAR MODEL FOR THE STUD OF THE STEERING ROD}

In the literature on abrasive wear at the contact of sliding bodies, many papers deal with various types of radial sliding bearings [59] to [70].

Fewer articles concern abrasive wear of various ball joints, including those used in medicine [71] to [78].

Watrin et al. [75] reported that the ball joint failure resulted from the interface degradation between the steel ball pin and its POM socket. Such wear was caused by two mechanisms, the abrasion of the ball socket surface with the ball pin and plastic deformation due to the axial load.

In the literature, some authors combine the results concerning the resistance to motion with the results concerning the abrasive wear in a given frictional contact. For example, numerically studying the plane elastic contact problem to determine the contact strength and tribological durability of sliding bearings, Chernets et al. [79] found that both contact angles and maximum contact pressures almost linearly depended on the load, and the durability weakened nonlinearly with load enhancement. The authors proposed the characteristic function of wear resistance of materials for discrete values of specific friction forces established during tribological tests.

Other researchers [16] to [19], however, believe that although both types of results may depend on the same physicochemical properties of the mating bodies, and possibly also the presence of lubricant and impurities in the contact, they are independent of each other, particularly on the macro scale. Similarly, in this paper, we have decided not to make the model of wear in contact between steel stud and its POM bearing dependent on the friction forces occurring in such a contact zone.

The abrasive wear of loaded surfaces was modelled using the Archard law, described by Eq. (14), by Ejtehadi et al. [71], as cited by [75], for the contact interface in the POM/Carbone-based-steel couple.

$$
V_{w}=k_{A} \cdot F_{n} \cdot s_{w},
$$


where $V_{w}$ is the worn volume $\left[\mathrm{mm}^{3}\right], F_{n}$ the normal applied load [N], $s_{w}$ the sliding distance [mm], and $k_{A}$ the wear coefficient $\left[\mathrm{mm}^{2} \mathrm{~N}^{-1}\right]$.

The modified Archard law in the form of Eq. (15) was used by the other authors, including [76] to [78], as cited by [75], for the evaluation of the wear depth.

$$
\mathbf{h}_{\mathbf{w}}\left(R_{s}, \theta_{t}, \varphi_{t}\right)=k_{A} \cdot \mathbf{L}_{\mathbf{w}}\left(R_{s}, \theta_{t}, \varphi_{t}\right) \cdot \mathbf{p}_{\mathbf{w}}\left(R_{s}, \theta_{t}, \varphi_{t}\right),
$$

where $\mathbf{h}_{\mathbf{w}}\left(R_{s}, \theta_{t}, \varphi_{t}\right)$ is the evolution of radial dimension of the ball socket surface during one cycle [mm], $\mathbf{L}_{\mathbf{w}}\left(R_{s}, \theta_{t}, \varphi_{t}\right)$ the sliding distance of the ball socket point during the cycle $[\mathrm{mm}], \mathbf{p}_{\mathbf{w}}\left(R_{s}, \theta_{t}, \varphi_{t}\right)$ the normal pressure applied on the ball socket element [MPa], $\theta_{t}, \varphi_{t}$ the angle coordinates of the sphere [rad], and $R_{s}$ the ball pin radius [mm].

Watrin et al. [75] proposed a relation Eq. (16) between the wear coefficient $k_{A}$ and the sliding distance $L_{w}$.

$$
k_{A}=6 \cdot 10^{-7} \cdot L_{w}^{0.58} .
$$

In the present study, it was assumed that the linear wear intensity $I_{h i}$ for both the steel stud and its POM bearing can be calculated using Eq. (17).

$$
I_{h i}=k_{i} \cdot p_{a}^{2} ; \quad i=1,2,
$$

where $k_{1}$ and $k_{2}$ are the wear intensity factors for the stud and its bearing, respectively, and $p_{a}$ is the averaged pressure in the contact zone between the ball stud and its bearing $[\mathrm{Pa}]$.

The wear intensity factor $k_{i}$ characterizing the linear wear intensity $I_{h i}$ was estimated from Eq. (18).

$$
\begin{aligned}
& W_{i}=w_{z} \cdot t_{c o r n}=I_{h i} \cdot S \cdot \sum_{j=1}^{M} v_{b}(j) \cdot t_{u}(j) \Rightarrow \\
& k_{i}=\frac{W_{i}}{R_{b} \cdot p_{a} \cdot \sum_{j=1}^{M} v_{b}(j) \cdot t_{u}(j)},
\end{aligned}
$$

where $w_{z}=I_{h i} \cdot S \cdot v_{b}^{\text {aver }}$ is volumetric wear rate $\left[\mathrm{m}^{3} \cdot \mathrm{s}^{-1}\right]$, $v_{b}^{\text {aver }}=l_{z} / t_{\text {corn }}$ average speed of the bearing relative to the ball stud during all analysed time of driving $\left[\mathrm{m}^{3} \cdot \mathrm{s}^{-3}\right]$, $t_{\text {corn }}$ summarized time of driving during cornering $[\mathrm{s}], \quad l_{z}=v_{b}^{\text {aver }} \cdot t_{\text {corn }}=\sum_{j=1}^{M} v_{b}(j) \cdot t_{u}(j)$ is wear distance represented by the ${ }^{j=1}$ assumed formula $[\mathrm{m}], W_{i}$ volumetric wear of the ball stud $(i=1)$ or its bearing $(i=2)\left[\mathrm{m}^{3}\right], S=R_{b} / p_{a}$ the contact area between the ball stud and its bearing $\left[\mathrm{m}^{2}\right]$, and $R_{b}$ reaction in contact between the ball stud and its bearing [N].

The majority of the encountered wear laws, discussed by Mukras [80], required determining contact pressure and the sliding amounts between the mating surfaces. The contact pressure can be determined using various methods, including the popular FEM [81] to [96], the less used elastic foundation model (EFM) [83] and [97] to [103], and the boundary element method (BEM) [104] to [106], and other less popular analytical procedures, like the semi-analytical method (SAM) [107]. The common problem of unwanted stress singularities is usually prevented by applying pressure instead of single point (node) loading [85]. In this study, the FEM was utilized to determine contact pressure in the contact zone between the stud ball end and its bearing.

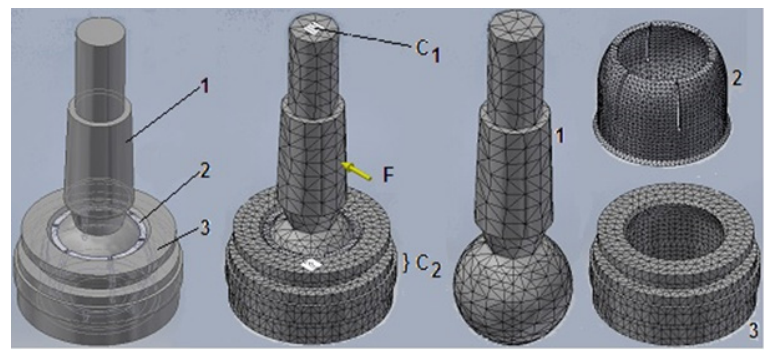

Fig. 4. FEM model of contact between rotating steel ball stud 1 and its POM bearing 2 fixed in the steel body 3

The normal contact pressure in a specific contact zone can be strongly affected by a load distribution in a complex object involving several or even several dozen components. In cases of rolling bearings or complex shapes of 3D surfaces mating under frictional conditions, the effective stiffness, sometimes in the matrix form, is utilized to represent the relationship between the external load and the resultant or averaged relative displacement of the object components. In the case of a rolling bearing, such stiffness is influenced by the number of rolling components, the distribution of the load on the individual bearing elements, the presence of grease, and preload. In the case of a conformal joint, the shape of the mating surfaces can be complicated by the presence of various grooves facilitating lubricant distribution, the presence and type of lubricant, the presence of a preload in the form of a tight-fitting between stud ball end, and its bearing. In the case of worn surfaces due to abrasive wear, such tight-fitting become the loose one.

Some researchers conducted studies on the load distribution and stiffness characteristics of the rolling bearings [108] to [110]. Their findings might also be useful for rod ends with rolling bearing, described, inter alia, in [111] and [112].

For these two issues, various methods can be used, including the statics analytical method (SAM), quasi-statics numerical method, and quasi-statics analytical method (QAM). 
The SAM hypothetically assumed the local load distribution. The effects of the preload and the variation of the contact angle are not usually considered in the traditional SAM [113]. That method was utilized by Palmgren [114], Houpert [115], and Hernot et al. [116], also in problems needed considering an effect of preload on the bearing stiffness matrix [117] to [120].

The quasi-statics numerical method hypothetically assumed the rigid body displacement of the inner ring.

Such an approach introduced by Jones [121] was used by Li et al. [122], Fang et al. [123], Tang [124], and Feng et al. [125].

Neol et al. [126] gave an analytical expression of quasi-static stiffness of the rolling bearings.

To limit the time requirement of the quasi-statics numerical method, the quasi-statics analytical method (QAM) utilizing various analytical algorithms or models were applied by Sheng et al. [127], Zhang et al. [128] and [129], Fang et al. [130], Cheng et al. [131], Jedrzejewski and Kwasny [132], Zhang et al. [133], Ren et al. [134].

The QAM can also be based on models elaborated using the Finite Element Method. Such an approach was utilized by Guo and Parker [135], and by Daidié et al. [136].

Wang et al. [137] proposed an improved quasidynamic model for the ACBBs to obtain a more accurate load distribution of them.

Liu et al. [113] utilized an analytical calculation method (SAMCA) for the load distribution and stiffness of a preloaded ACBB with combined loads, including the radial and axial ones.

The contact pressure was obtained from the steady-state analysis using the FEM model of the contact between the rotating steel stud ball end and its POM bearing fixed in the steel body (Fig. 4). The material model for the stud and the body utilized the linear isotropic model of steel. In such a model, the density was equal to $7800 \mathrm{~kg} / \mathrm{m}^{3}$, the Young modulus to $210,000 \mathrm{MPa}$ and the Poisson number to 0.3 [11]. The material model for the bearing utilized the linear isotropic model of POM with density of $1410 \mathrm{~kg} /$ $\mathrm{m}^{3}$, the Young modulus was equal to $3000 \mathrm{MPa}$, the Poisson ratio was equal to 0.42 , respectively [11].

The linear behaviour of steel ball and POM socket was also assumed by Watrin et al. [75] for the finite element analysis of contact pressure distribution during their studies on the ball pin and plastic socket contact in a ball joint.

The grid of the tetrahedral finite elements was generated automatically by the program. Each finite element comprises nodes with three degrees of freedom, such as displacements $u_{x}, u_{y}, u_{z}$ along the respective main axes $X, Y, Z$ of the global set of coordinates.

The boundary conditions were as follow: $\mathrm{C}_{1}$ is the top, and the neighbouring cylindrical surfaces of the ball stud end could move only perpendicular to the axis of the stud, $\mathrm{C}_{2}$ the cylindrical surface of the steel body was fixed, and $\mathrm{C}_{3}$ the conical surface of the stood was loaded by the constant horizontal force $F$. Such a force can reach values up to $500 \mathrm{~N}$ [49], 1540 $\mathrm{N}$ [50] or even $2000 \mathrm{~N}$ [11].

The grid of FEs and boundary conditions are presented in Fig. 4.

While driving according to the described earlier course, the necessity to make sudden turns could occur sporadically. Therefore, it was assumed for further analysis that the load on the contact zone between the stud ball end and its bearing was of quasistatic nature. However, during analysis, the non-linear character of the contact stiffness between the stud ball end and its POM bearing was also considered, by using a non-linear computational algorithm [138] to solve the problem of contact status and contact pressure for each contact element in the contact zones between mating surfaces of the components. The necessity to consider the nonlinear character of contact stiffness is usual for rolling bearing. According to Liu et al. [113], the rating speed had a significant effect on the contact angle and stiffness of roller bearings, especially for the high-speed range. The enhancement of macroscopic loads not only increased the contact loads but also enhanced stiffness of rolling bearing. The selection of the calculation method also influenced the obtained contact pressure values for the given values of macroscopic loads and geometrical parameters of the contacting elements [113]. An unexpectedly received calculation method (e.g., a linear algorithm assuming a linear relationship between deformation and stress) resulted in obtaining the most frequently overestimated values of contact pressures, especially at high loads.

The size of each contact element was strictly correlated to the size of the directly underlying volumetric finite element generated for material lying beneath the surface on which such a contact element was formed, as described in [138].

The effect of finite element size on the convergence of solution was studied, assuming the maximal value of mean macroscopic contact pressure $p_{m}$ between the stud ball end and its bearing under loading by the force $F$ (Fig. 4) equal to $500 \mathrm{~N}$, as the criterion. Such a macroscopic contact pressure related to the area comprising both contact areas of deformed 
loaded asperities and the nearest adjacent areas completely separated by the grease layer.

After obtaining the solution, the 3D triangular finite contact elements associated with the inner spherical surface of the POM insert were recorded together with the coordinates of the corner nodes $X_{e}, \quad Y_{e}$ and $Z_{e}$ of the given $e^{\text {th }}$ finite contact element, the contact status $C S_{e}\left(C S_{e}=1\right.$, when in contact and $C S_{e}=0$, when not in contact) of this element and the value of the contact pressure $p_{e}$. The coordinates $X_{e}$, $Y_{e}, Z_{e}$ of the corner nodes allowed estimating the 3D triangle area close to area $A_{e}$ of the given $e^{\text {th }}$ finite contact element. For each finite contact element, the area of said triangle was multiplied by the contact pressure for a given contact element and the contact status. Then these products were summed to give the value of $S_{1}$. Moreover, the area of said triangle was multiplied by the contact status of a given finite contact element, and then such products were summed to obtain the value of $S_{2}$. Dividing the $S_{1}$ by the $S_{2}$ allowed obtaining the estimated value of mean contact pressure. A more coarse but easier estimate can be obtained using Eq. (19).

The 3D triangle contact elements with the bond option were introduced between the bearing and the body, while between the stud and this bearing, similar contact elements with frictional option were used. The surface-to-surface type with asymmetric option were utilized. Therefore, the flexible target elements were applied to the stud ball end 1 and the inner surface of steel body 3 . The deformable contact elements were applied to the inner and outer surface of POM bearing 2 (Fig. 4). It was used the default values of parameters characterizing behaviour of contact elements [138].

The friction coefficient between the steel body and the POM bearings was assumed to be equal to 0.22 [139]. Under small slipping, the friction coefficient does not change with applied force [140]. Therefore, the friction coefficient was independent of the eventual preloading of the assembly [11].

An averaged pressure was calculated from Eq. (19).

$$
p_{a}=\frac{1}{K} \sum_{e=1}^{K} p_{e}
$$

where $p_{e}$ is contact pressure on the $e^{\text {th }}$ contact element, and $K$ number of contact elements loaded by contact pressure (based on status number: 1 - in contact, 0 not in contact, assigned to each contact element after solution convergence).

The wear $W_{1}$ of the ball end of the steel stud was calculated as a difference between the volumes of a new ball and a worn ball bordered by its maximal tangential outer surface. It was assumed that the shape of the new ball-end volume is a sphere of diameter $D_{1}$. The worn ball end volume is a rotated ellipse with two main diameters equal to $D_{1}$ and the third main diameter equals the difference $D_{1}-\Delta D_{1} . \Delta D_{1}$ is the change of the measured outer diameter due wear process. Therefore, the wear of the ball end of the steel stud was estimated from Eq. (20).

$$
W_{1}=0.5 \cdot \pi \cdot D_{1}^{2} \cdot \Delta D_{1}
$$

The wear $W_{2}$ of the POM bearing was calculated as a difference between volumes contained within the worn and new bearing/seat and bordered by its minimal tangential inner surface. It was assumed that the shape of the new bearing/seat volume is a sphere of diameter $D_{2}$. The worn bearing/seat volume is a rotated ellipse with two main diameters equal $D_{2}$ and the third main diameter equal to the sum $D_{2}+\Delta D_{2}$. The $\Delta D_{2}$ is the change of the measured inner diameter due the wear process occurring between the ball end of the steel stud and its POM bearing. Therefore, the wear of the ball end of the steel stud was estimated from Eq. (21).

$$
W_{2}=0.5 \cdot \pi \cdot D_{2}^{2} \cdot \Delta D_{2}
$$

\subsection{The Effect of Lubrication on the Contact Pressure in Contact Zone}

The effect of lubrication in contact zone under mixed friction conditions on average contact pressure is rather small compared with the case of unlubricated contact, as shown in Zhang et al. [141].

According to Otero et al. [142], determination friction forces in mixed lubrication for highly loaded non-conformal contacts requires, inter alia, a load share function determining the fraction of load supported by the lubricant film.

For point contacts, Zhu and $\mathrm{Hu}$ [143], as cited in [142], proposed such a function in the form of Eq. (22).

$$
f_{?}=\frac{1.21 \cdot \lambda^{0.61}}{1+0.37 \cdot \lambda^{1.26}},
$$

where $\lambda$ and the specific lubricant film thickness determined from Eq. (23) [142].

$$
\lambda=\frac{h_{0}}{\sqrt{\sigma_{1}^{2}+\sigma_{2}^{2}}},
$$

where $h_{0}$ the minimum lubricant film thickness [142], and $\sigma_{1}, \sigma_{2}$ the root mean square (RMS) roughness of the mating surfaces 1 and 2 , respectively [142]. 
For line contacts, Castro and Seabra [144], as cited in [142] proposed such a function in the form of Eq. (24).

$$
f_{\lambda}=0.84 \cdot \lambda^{0.23} \text {. }
$$

According to [142], both such functions did not differ significantly.

The actual spherical surfaces, both of stud ball end and of its bearing, as separate mechanical components, are characterized by roughness being the component of surface texture, excluding waviness and deviation of form [145]. The rough surface can be modelled using various methods. The model directly created using the FEM was proposed by Thompson [146]. In the model, the rough surface was formed first by using the nodal or elemental set, then the height of the nodes was changed randomly, which resulted in the formation of the surface with sharp peak asperities bringing extreme stress.

Another approach is the application of the random Gaussian height distribution (GHD) equation for generation of the matrix of roughness points (2D), followed by developing the $3 \mathrm{D}$ rough surface model. Using appropriate CAD software (CATIA, SolidWorks, among others), the cloud of rough surface points is transformed into a 3D surface form and then converted into the 3D solid form. This approach was utilized in [147] to [153].

The rough asperities can be modelled as the set of the elasto-plastically deformed hemispheres [154] to [157], hemi-ellipsoids [157] and [158] or paraboloids [159] and [160] with various distributions.

The contact between the stud ball end and its bearing belongs to the group of conformal joints. Therefore, to estimate the effect of lubrication occurrence in the contact zone between stud ball end and its POM bearing on the contact pressure values therein, the following assumptions were made.

The content of moisture, debris, and contaminants in the grease was constant, and all these inclusions were collected in the grease outside the contact zone, e.g., in grooves to facilitate spreading grease. This assumption was made to avoid unnecessarily complicating the model and to neglect such an effect on the wear process.

The temperature in the contact area between the stud ball end and its bearing was constant and did not affect the rheological properties of the grease and the wear of the mating surfaces and the grease itself.

The mapping of the mixed lubrication conditions in the contact between the stud ball end and its POM bearing was made by considering the movement of a flat, rigid, and smooth surface on a rough surface, presented as a set of model asperities (Fig. 5). Such a movement was under constant sliding speed $U$.

The space between such surfaces was divided into two areas with different lubrication mechanisms: the first one containing modelled asperities under boundary lubrication conditions and the second one containing lubricating microclines under hydrodynamic lubrication conditions.

The load on the area of a single asperity and its environment containing microclines of the lubricant is transferred by the force from the plastic deformations of the asperity in contact with the rigid plane and the lifting force of the lubricating microclines.

The layer of lubricant around the centre of the asperity top was so thin that boundary lubrication processes occurring in such an area were not subject to the laws of hydrodynamics. The thickness $h_{f}^{a v}$ of the layer was independent on the normal load $N$ (Fig. 5a). The distribution of unit pressures in the presence of this thin layer was very close to the distribution of Hertz pressure, arising at the contact of non-lubricated surfaces.

In the region of the microclines, the layer of lubricant was sufficiently thick, and the principles of hydrodynamic lubrication were applicable to it.

The asperities were modelled as the elastic-plastic hemispheres evenly distributed over the contact zone (Fig. 5b).

The radius $R_{a s p}$ of such a hemisphere was equal to the roughness parameter $R a$ equal to $5 \mu \mathrm{m}$.

The distance $R_{0}$ between the centres of adjacent hemispheres was equal to the half of roughness parameter $R S m$ equal to $0.2 \mathrm{~mm}$.

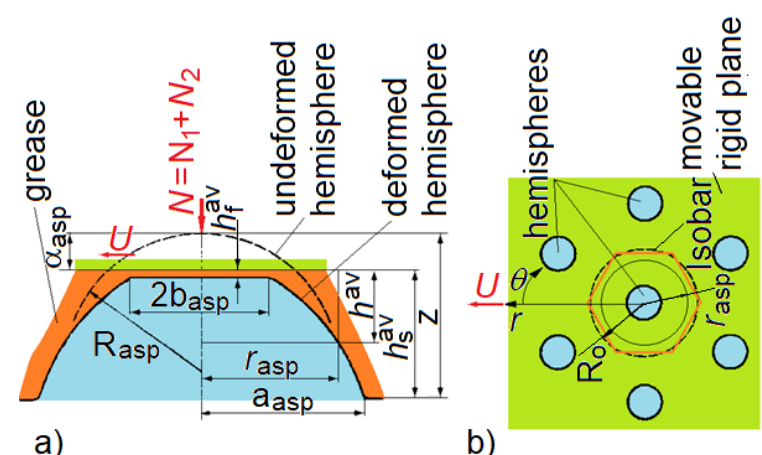

Fig. 5. Model of contact between a rough surface and a rigid smooth plane; a) model of the grease layer separating rough surface asperities from a flat, rigid, and smooth plane, b) model of the distribution of asperities in contact with a movable rigid plane

A circular isobar was created around each asperity when the maximal thickness $h_{s}^{a v}$ of lubricant occurred 
(Fig. 5b). It was assumed that $h_{s}^{a v}=0.5 R a$. It was also assumed that $h_{s}^{a v}=0.01 h_{f}^{a v}$.

The normal load $N_{1}$ on the contact of a single asperity with the rigid plane (Fig. 5a) was estimated from Eq. (25) [161], as cited in [162].

$$
N_{1}=2 \cdot \pi \cdot H_{\text {POM }} \cdot R_{\text {asp }} \cdot \alpha_{\text {asp }},
$$

where $R_{a s p}=R a$ is the radius of the hemisphere modelling the asperity, $H_{P O M}=150 \mathrm{MPa}$ hardness of POM [163], and $\alpha_{\text {asp }}$ deformation of the centre of the contact area, called 'roughness susceptibility' (Fig. 5a), defined by Eq. (26) [162].

$$
\alpha_{a s p}=z-\left(h_{s}^{a v}-h_{f}^{a v}\right),
$$

where $z$ is the height of the undeformed hemisphere modelling an asperity (Fig. 5a).

The roughness susceptibility $\alpha_{a s p}$ was determined from Eq. (27) [164], as cited in [162].

$$
\alpha_{a s p}=R_{a s p} \cdot\left(\frac{H_{P O M}}{E_{P O M}}\right)^{2} \cdot\left(1-v_{P O M}^{2}\right),
$$

where $E_{P O M}=3000 \mathrm{MPa}$ is the tensile modulus of POM [163], and $v_{P O M}=0.35$ the Poisson number of POM, as assumed.

The number $N_{a s p}$ of asperities being in contact with the rigid plane was estimated from Eq. (28).

$$
N_{a s p}=\frac{2 \cdot \pi \cdot D_{2}^{2}}{4 \cdot \pi \cdot R_{0}^{2}},
$$

where $R_{0}=0.5 \cdot R S m=0.1 \mathrm{~mm}$ is the distance between the centres of adjacent hemispheres modelling asperities.

The average thickness $h_{a v}$ of lubricant (Fig. 5a) was described by Eq. (29) [161], as cited in [162].

$$
h_{a v}= \begin{cases}h_{f}^{a v} \cdot\left(1+\frac{r_{a s p}^{2}}{2 \cdot R_{a s p} \cdot h_{f}^{a v}}\right), & \text { for } b_{a s p} \leq r_{a s p} \leq a_{a s p}, \\ h_{s}^{a v}, & \text { for } a_{a s p} \leq r_{a s p} \leq R_{0}\end{cases}
$$

where $r_{a s p}$ is the current value of the radius of the projection of the hemisphere onto the rigid plane (Fig. $5)$, and $b_{a s p}$ the boundary radius of the area of the plastically deformed contact zone of the hemisphere modelling asperity (Fig. 5a); it was determined from Eq. (30) [161], as cited in [162].

$$
b_{a s p}=\sqrt{2 \cdot R_{a s p} \cdot \alpha_{a s p}},
$$

where $a_{\text {asp }}$ is the radius of the base of the hemisphere (Fig. 5a); considering Eq. (29), it can be estimated from Eq. (31) $\dot{a}_{a s p}=\sqrt{2 \cdot R_{a s p} \cdot\left(h_{s}^{a v}-h_{f}^{a v}\right)}$,
The dependency between the lubricant thickness $h$ and pressure $p$ for the hydrodynamic lubrication conditions was described by average Reynold's Eq. (32) [165] and [166], as cited in [162].

$$
\begin{aligned}
& \frac{1}{r_{a s p}} \cdot \frac{\partial}{\partial r_{a s p}}\left(r_{a s p} \cdot h_{a v}^{3} \cdot \frac{\partial p}{\partial r_{a s p}}\right)+\frac{1}{r_{a s p}^{2}} \cdot \frac{\partial}{\partial \theta}\left(h_{a v}^{3} \cdot \frac{\partial p}{\partial \theta}\right)= \\
& 12 \cdot \eta_{e q} \cdot U \cdot \frac{\partial h_{a v}}{\partial r_{a s p}}
\end{aligned}
$$

where $U$ is the sliding speed rigid plane relative to the rough surface (Fig. 5). It was assumed that it can reach values up to $0.03 \mathrm{~m} / \mathrm{s}$, and $\eta_{e q}=0.126 \mathrm{~Pa} \cdot \mathrm{s}$ the equivalent dynamic viscosity for the lithium grease determined according to the procedures described in [167]. The lithium grease rheological properties were modelled using the Herschel-Bulkley model given by Eq. (33) [168].

$$
\tau=\tau_{0}+m_{1} \cdot(\dot{\gamma})^{n},
$$

where $\tau_{0}=611.26 \mathrm{~Pa}, m_{1}=3.201 \mathrm{~Pa} \cdot \mathrm{s}^{\mathrm{n}}, n=0.616$ are parameters of the Herschel-Bulkley model for the UM185Li2 grease [168]. The dynamic viscosity of its base oil at room temperature was assumed to be about $0.1 \mathrm{~Pa} \cdot \mathrm{s}$.

For the region $a_{a s p} \leq r_{a s p} \leq R_{0}$ where $h_{s}^{\text {aver }}$ was constant, the solution of Eq. (29) took the form of Eq. (34) [161], as cited in [162].

$$
p=p_{m}+\frac{12 \cdot \eta_{e q} \cdot U}{a_{a s p}} \cdot C_{f 1} \cdot\left(\frac{R_{0}}{a_{a s p}}-\frac{r_{a s p}}{a_{a s p}}\right) \cdot \cos \theta,
$$

where $\theta$ is the current value of angle around the axis of the hemisphere modelling an asperity (Fig. 5b), $p_{m}$ mean macroscopic pressure over the entire lubricated area, $C_{f 1}$ constant factor determined from Eq. (35) [161], as cited in [162].

$$
C_{f 1}=\frac{\left(\frac{h_{f}^{\text {aver }}}{a_{a s p}}\right) \cdot\left(0.5-0.3 \cdot k_{a s p}\right)-0.5\left(\frac{h_{f}^{\text {aver }}}{a_{a s p}}\right)}{\left(\frac{h_{f}^{\text {aver }}}{a_{a s p}}\right)^{3}\left[\left(\frac{R_{0}}{a_{a s p}}\right)^{2}+1\right]+\left(\frac{h_{f}^{\text {aver }}}{a_{a s p}}\right)^{2} \cdot\left(1+k_{\text {asp }}\right)^{3}\left[\left(\frac{R_{0}}{3}\right)^{3}-1\right]},
$$

where $k_{a s p}$ is constant factor determined from Eq. (36) [161], as cited in [162].

$$
k_{a s p}=\frac{a_{a s p}^{2}}{2 \cdot R_{a s p} \cdot h_{f}^{\text {aver }}},
$$

For the region $a_{a s p} \leq r_{a s p} \leq R_{0}$ where $h_{s}^{\text {aver }}$ varied, the solution of Eq. (29) took the form (37) [161], as cited in [162]. 
$p=p_{m}+\frac{12 \cdot \eta_{e q} \cdot U}{a_{a s p}}\left(-\frac{r_{a s p} \cdot a_{a s p}}{5 \cdot h_{\text {aver }}^{2}}+C_{f 2} \cdot \frac{r_{a s p}}{a_{a s p}}\right) \cdot \cos \theta$,

where $C_{f 2}$ is a constant factor determined from Eq. (38) [161], as cited in [162].

$C_{f 2}=\left[\left(\frac{R_{0}}{a_{a s p}}\right)^{2}-1\right] \cdot C_{f 1}+\frac{1}{5 \cdot\left(\frac{h_{f}^{\text {aver }}}{a_{a s p}}\right)^{2} \cdot\left(1+k_{\text {asp }}\right)^{2}}$.

A normal load $N_{2}$ of a single asperity arising because of hydrodynamic phenomena accompanying the displacement of a single unevenness in relation to a rigid plane was determined from Eq. (39) [161], as cited in [162].

$$
N_{2}=\int_{b_{a s p}}^{R_{0}} \int_{0}^{2 \pi}\left|p \cdot r_{a s p}\right| d r_{a s p} d \theta
$$

The total normal load of contact zone was estimated from Eq. (40).

$$
N=N_{a s p} \cdot\left(N_{1}+N_{2}\right) \text {. }
$$

The average contact pressure $p_{a s p}^{a v}$ resulted from load carried out by asperities in contact zone was estimated from Eq. (41).

$$
p_{a s p}^{a v}=\frac{4 \cdot S_{2}}{2 \cdot \pi D_{2}^{2}} \cdot \frac{N_{a s p} \cdot N_{1}}{N_{a s p} \cdot \pi \cdot b_{a s p}^{2}}=\frac{2 \cdot S_{2} \cdot N_{1}}{\pi^{2} D_{2}^{2} \cdot b_{a s p}^{2}} .
$$

\subsection{The Squeeze Film in Contact Zone between the Stud Ball End and Its Bearing}

Clarke and Bell [169] elaborated a model for the prediction of the friction in a ball joint operating under very high loads and rotations at very low speeds, including zero speed, thus, in the mixed and boundary lubrication regimes. The model considered the effect of a squeeze film. Using this model for studies on the hydraulic motors with various surface finishes on the ball joints, they found that friction in the ball joints was strongly affected by various surface qualities.

In the present study, it was assumed that after the axial load on the tie rod end, the conditions necessary for the mixed friction to occur in the contact zone of the stud ball end with its bearing are created. First, during their rotation relative to each other, the lubricant layer is pressed out of the gap between them. Then a squeeze film is formed in the fracture, accompanied by the production of a normal pressure distribution.

Similarly, to the case of rotation of the stud ball end relative to its bearing under lubrication, it was also assumed that the effect of content of moisture, debris, and impurities in the grease, and the temperature in contact zone on the rheological properties of grease and the wear process was neglected.

Although in fact, the contact zone is closer to the sphere segment, the research on squeeze fill was carried out using the hemisphere model, assuming that this difference does not significantly affect the obtained pressure values.

To estimate values of this pressure, the model like that developed by Walicki and Walicka [170] was adopted, while the then-occurring rotational movement of the stud ball end in relation to its bearing takes place under conditions of very low rotational speed, so its effect resulting from the accompanying it the hydrodynamic interactions in the grease layer on the pressure distribution may be omitted.

The model of hemispherical contact between the steel stud ball end and its POM bearing operating under a squeeze film of grease was shown in Fig. 6 . For the further analysis, it was assumed that squeezing took place at an averaged speed.

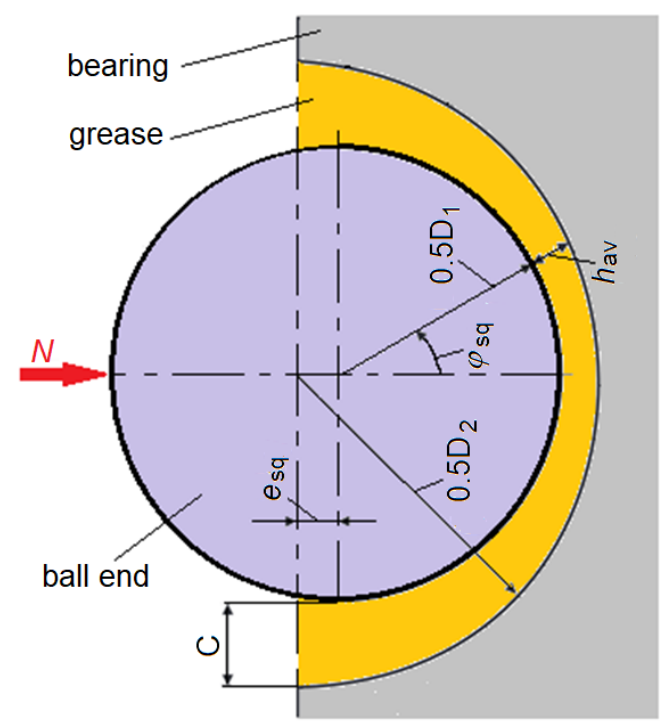

Fig. 6. Model of hemispherical contact between the stud ball end and its POM bearing operating under a squeeze film of grease;

$$
C=0.5 \cdot\left(D_{2}-D_{1}\right), \varepsilon_{s q}=e_{s q} / C, \dot{\varepsilon}_{s q}=d \varepsilon_{s q} / d t .
$$

The pressure was estimated from Eq. (42) [170]. 


$$
\begin{aligned}
& p=\frac{\eta_{e q} \cdot\left(0.5 \cdot D_{1}\right)^{4} \cdot \dot{\varepsilon}_{s q}}{C^{2}} \cdot \frac{3}{\varepsilon_{s q}} \cdot\left\{\frac{1}{\left(1-\left(\cos \varphi_{s q}\right)^{2}\right)}\right. \\
& \left.-1+6 \cdot l^{*} \cdot\left[\frac{1}{\left(1-\left(\cos \varphi_{s q}\right)^{4}\right)}-1\right]\right\},
\end{aligned}
$$

where $l^{*}=0.1$ is dimensionless parameter [170], $C=0.5 \cdot\left(D_{2}-D_{1}\right)$ the radial clearance between stud ball end and its bearing, $e_{s q}$ the eccentricity, $\varepsilon_{s q}=e_{s q} / C$ the eccentricity ratio, and $\dot{\varepsilon}_{s q}=d \varepsilon_{s q} / d t$ the time derivative of the eccentricity ratio $\varepsilon_{s q}$.

The average pressure was determined from Eq. (43).

$$
p_{a v} \approx \frac{\int_{0.001}^{\pi / 2} p \cdot \varphi_{e q} \cdot d \varphi_{e q}}{\int_{0.001}^{\pi / 2} d \varphi_{e q}} .
$$

The loading carried out was estimated from Eq. (44) [170].

$$
\begin{aligned}
N= & \frac{\eta_{e q} \cdot\left(0.5 \cdot D_{1}\right)^{4} \dot{\varepsilon}_{s q}}{C^{2}} \cdot \frac{6 \pi}{\varepsilon_{s q}^{3}} \cdot\left\{\frac{\varepsilon_{s q}}{1-\varepsilon_{s q}}-\frac{\varepsilon_{s q}^{2}}{2}\right. \\
& \left.+\ln \left(1-\varepsilon_{s q}\right)+6 \cdot l^{* 2} \cdot\left(\frac{1}{3}\left[\frac{1}{\left(1-\varepsilon_{s q}\right)^{3}}-1\right]-\frac{\varepsilon_{s q}^{2}}{2}\right)\right\} \cdot
\end{aligned}
$$

Eq. (44) enabled estimating the average value of the time derivative of the eccentricity ratio $\dot{\varepsilon}_{s q}$ for the given value of force $N$ loading the contact zone between the stud ball end and its bearing during squeezing of grease layer between them. This allowed determining values of pressure $p$ from Eq. (42) and of average pressure $p_{a v}$ from Eq. (43).

\section{LATERAL FORCES LOADING WHEELS DURING CORNERING}

Lateral forces loading wheels are important from the point of view of driving with a varying motion trajectory of the vehicle. Using a two-degrees of freedom (DOF) planar two-track model with a nonlinear magic tire formula [171] showed that the better adhesion capacities of tires worsened both lateral vehicle stability and increased rollover propensity, which both were highly affected by both the suspension parameters and the road excitation inputs.

Rega et al. [172] reported that the vehicle steering bifurcation analysis usually utilized the nonlinear autonomous vehicle model based on the two degrees of freedom (2DOF) linear vehicle model. The driving effect on steering bifurcation characteristics is omitted in such a model. However, in real driving conditions, the tires can provide various lateral forces. The steering bifurcation mechanism neglecting the driving effect cannot fully reveal the vehicle steering and driving bifurcation characteristics.

In the present study, the model of vehicle cornering was assumed to be similar to the 4-wheel model used by Nguyen [173]. The model is presented in Fig. 7. The geometry of the model is characterized by vehicle parameters $t_{f}$ and $t_{r}$ (the front and rear track widths) equal to $1.2 \mathrm{~m}$. The distance between wheel axes is equal to $L=2850 \mathrm{~mm}$, and the coordinates of the centre of the gravity are $a_{f}=1120 \mathrm{~mm}$ and $a_{r}=$ $1730 \mathrm{~mm}$, respectively. Tire force was based solely on a slip angle. Tire forces were taken as perpendicular to the velocity at each of the individual tires. The motion of the vehicle is described by the set of Eqs. (45) to (54) [173]. After their time integration, the variables $\omega$ and $\beta$ were obtained. This process was iterative, as the angle $\delta_{f}$ was determined also in an iterative manner.

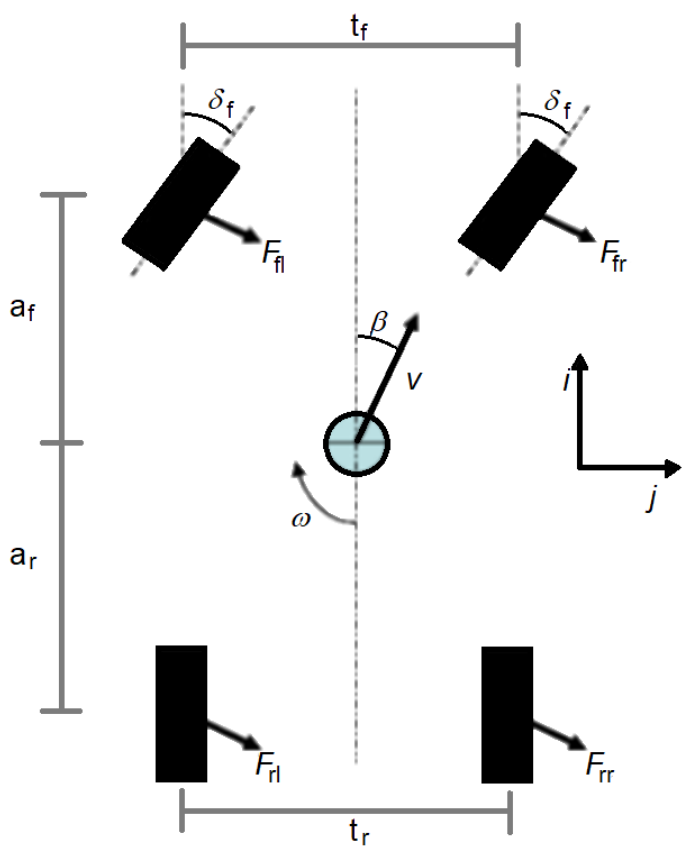

Fig. 7. The model of cornering vehicle

$$
\begin{aligned}
m v\left(\frac{d}{d t} \beta+\omega\right)= & F_{f r} \cos \left(\beta_{f r}-\beta\right)+F_{f l} \cos \left(\beta_{f l}-\beta\right) \\
& +F_{r r} \cos \left(\beta_{r r}-\beta\right)+F_{r l} \cos \left(\beta_{r l}-\beta\right),
\end{aligned}
$$




$$
\begin{aligned}
& I_{z} \frac{d}{d t} \omega=F_{f r}\left(\sqrt{a_{f}^{2}+0.25 t_{f}^{2}} \sin \left(0.5 \pi-\beta_{f r}+\tan ^{-1}\left(0.5 t_{f} a_{f}^{-1}\right)\right)\right) \\
& +F_{f l}\left(\sqrt{a_{f}^{2}+0.25 t_{f}^{2}} \sin \left(0.5 \pi-\beta_{f l}+\tan ^{-1}\left(0.5 t_{f} a_{f}^{-1}\right)\right)\right) \\
& -F_{r r}\left(\sqrt{a_{f}^{2}+0.25 t_{f}^{2}} \sin \left(0.5 \pi-\beta r r+\tan ^{-1}\left(0.5 t_{r} a_{r}^{-1}\right)\right)\right) \\
& -F_{r l}\left(\sqrt{a_{f}^{2}+\left(0.5 t_{r}\right)^{2}} \sin \left(0.5 \pi-\beta r l+\tan ^{-1}\left(0.5 t_{r} a_{r}^{-1}\right)\right)\right) \text {, } \\
& \beta_{f r}=\tan ^{-1}\left(\frac{v \cdot \sin (\beta)+a_{f} \omega}{v \cdot \cos (\beta)-0.5 t_{f} \omega}\right), \\
& \beta_{f l}=\tan ^{-1}\left(\frac{v \cdot \sin (\beta)+a_{f} \omega}{v \cdot \cos (\beta)+0.5 t_{f} \omega}\right), \\
& \beta_{f r}=\tan ^{-1}\left(\frac{v \cdot \sin (\beta)-a_{r} \omega}{v \cdot \cos (\beta)-0.5 t_{r} \omega}\right), \\
& \beta_{f l}=\tan ^{-1}\left(\frac{v \cdot \sin (\beta)-a_{r} \omega}{v \cdot \cos (\beta)+0.5 t_{r} \omega}\right), \\
& \alpha_{f r}=\tan ^{-1}\left(\frac{v \cdot \sin (\beta)+a_{f} \omega}{v \cdot \cos (\beta)-0.5 t_{f} \omega}\right)-\delta_{f}, \\
& \alpha_{f l}=\tan ^{-1}\left(\frac{v \cdot \sin (\beta)+a_{f} \omega}{v \cdot \cos (\beta)+0.5 t_{f} \omega}\right)-\delta_{f} \text {, } \\
& \alpha_{f r}=\tan ^{-1}\left(\frac{v \cdot \sin (\beta)-a_{r} \omega}{v \cdot \cos (\beta)-0.5 t_{r} \omega}\right), \\
& \alpha_{f l}=\tan ^{-1}\left(\frac{v \cdot \sin (\beta)-a_{r} \omega}{v \cdot \cos (\beta)+0.5 t_{r} \omega}\right),
\end{aligned}
$$

where $v=v_{\text {aver }}(j)$ is the average speed of vehicle $\left[\mathrm{m} \cdot \mathrm{s}^{-1}\right]$, and $I_{z}$ mass inertia moment of the vehicle relative to the vertical $z$ axis $\left[\mathrm{kg} \cdot \mathrm{m}^{2}\right]$.

During calculations, the average values of the slip angles were used: $\alpha_{f}=0.5\left(\alpha_{f r}+\alpha_{f l}\right)$ and $\alpha_{r}=0.5\left(\alpha_{r r}+\alpha_{r l}\right)$.

According to Nguyen [173], the Magic Tire Formula was used in general terms of Eq. (55) [171]. The index $m$ in equation (29) can assume the following values: $f$ for the front wheel or $r$ for the rear wheel, respectively.

$$
\begin{aligned}
F\left(\alpha_{m}\right)= & \left(a_{1} F_{z m}^{2}+a_{2} F_{z m}\right) \cdot \\
& \sin \left\langlea _ { 0 } \operatorname { t a n } ^ { - 1 } \left\{\frac{a_{3} \sin \left(2 \tan ^{-1}\left(F_{z m} a_{4}^{-1}\right)\right)}{\left(a_{0}\left(a_{1} F_{z m}^{2}+a_{2} F_{z m}\right)\right.} \alpha_{m}-\right.\right. \\
& \left(a_{6} F_{z m}+a_{7}\right)\left(1-a_{17} \operatorname{sgn}\left(\alpha_{m}\right)\right) \cdot \\
& \left(\frac{a_{3} \sin \left(2 \tan ^{-1}\left(F_{z m} a_{4}^{-1}\right)\right)}{a_{0}\left(a_{1} F_{z m}^{2}+a_{2} F_{z m}\right)} \alpha_{m}-\right. \\
& \left.\left.\left.\tan ^{-1}\left[\frac{a_{3} \sin \left(2 \tan ^{-1}\left(F_{z m} a_{4}^{-1}\right)\right)}{a_{0}\left(a_{1} F_{z m}^{2}+a_{2} F_{z m}\right)} \alpha_{m}\right]\right)\right\}\right\rangle,
\end{aligned}
$$

where for the wheel pressure equal to 35 psi, curvefitted parameters are the following: coefficients $a_{0}=1.3, a_{1}=-0.0115 \mathrm{~N}^{-1}, a_{2}=0.8447, a_{3}=-123.6505 \mathrm{~N}$, $a_{4}=14.273 \mathrm{~N}, a_{6}=-0.08073 \mathrm{~N}^{-1}, a_{7}=0.0272$ and $a_{17}=0.0594$ [171], as cited in [173].

The steering angle $\delta_{f}$ was estimated from Eq. (56) [173].

$$
\begin{aligned}
\delta_{f} & =\tan ^{-1}\left[a_{r} \cos (\beta) R^{-1}(j)\right] \\
& -\tan ^{-1}\left[a_{f} \cos (\beta) R^{-1}(j)\right]+\alpha_{r}-\alpha_{f},
\end{aligned}
$$

\section{RESULTS}

For the different values of turns radius, during vehicle cornering, some courses of the force $F$ loading the stud of the steering rod versus the steering angle $\delta$ were obtained. Fig. 8 shows the course for the average value of vehicle speed $v$ during cornering equal to $10.55 \mathrm{~m} \cdot \mathrm{s}^{-1}$ and Fig. 9 does this for the average value of $12.22 \mathrm{~m} \cdot \mathrm{s}^{-1}$. With the increase of the cornering radius $R$, the values of the force $F$ decrease almost linearly, and the changes of the force $F$ against the steering angle decrease. The increase of the averaged velocity $v$ with about $7 \%$ results in the increase of the force $F$ with about $30 \%$.

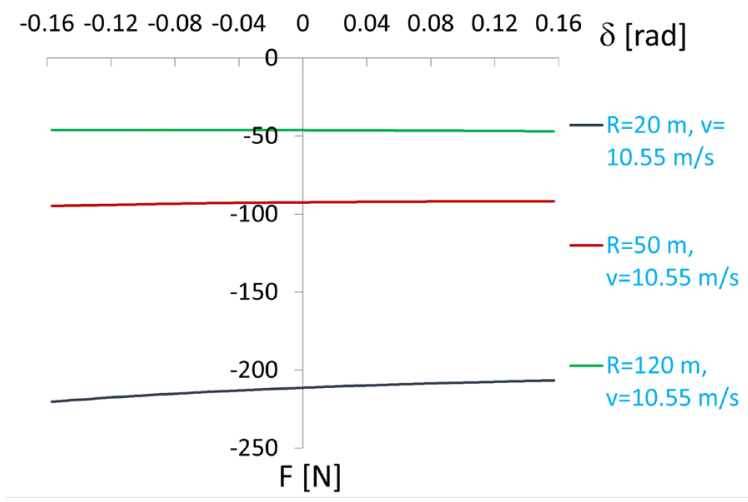

Fig. 8. The force $F$ loading the stud vs. the steering angle $\delta$ for various radiuses $R$ of cornering with the average value of vehicle speed $v=10.55 \mathrm{~m} \cdot \mathrm{s}^{-1}$.

The results of the study on the effect of a finite element size on the convergence of solution controlled by the maximum value of the mean macroscopic contact pressure $p_{m}$ between the stud and its bearing loaded by the force $F$ (Fig. 4) equal to $500 \mathrm{~N}$ were presented in Table 2 . 
Table 2. The effect of finite element size on the maximum contact pressure between the stud and its bearing

\begin{tabular}{ccc}
\hline $\begin{array}{c}\text { Iteration } \\
{[-]}\end{array}$ & $\begin{array}{c}\text { Average finite } \\
\text { element size }[\mathrm{m}]\end{array}$ & $\begin{array}{c}\text { Maximum value of mean macroscopic } \\
\text { contact pressure between the stud and } \\
\text { its bearing [MPa] }\end{array}$ \\
\hline 1 & 0.002 & 2.5848 \\
\hline 2 & 0.001 & 2.4393 \\
\hline 3 & 0.0007 & 2.6374 \\
\hline 4 & 0.0005 & 3.1686 \\
\hline 5 & 0.0004 & 3.3535 \\
\hline
\end{tabular}

It was assumed that the average finite element size equal $0.0005 \mathrm{~m}$ can allow the proper convergence of solution without unnecessarily increasing computation time and computing power involved.

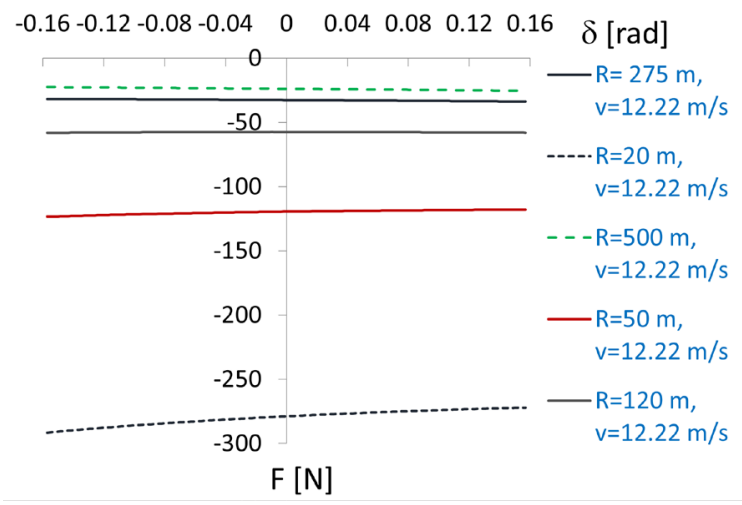

Fig. 9. The force $F$ loading the stud vs. the steering angle $\delta$ for different radiuses $R$ of cornering with the average value of vehicle speed $v=12.22 \mathrm{~m} \cdot \mathrm{s}^{-1}$

The resulting values of von Mises stresses in the model for the stud of steering rod loaded by force $F=300 \mathrm{~N}$ were presented in Fig. 10a for the complete assembly and in Fig. 10b for one without the stud. The calculated maximum value of such stresses equal to $53.1 \mathrm{MPa}$ occurred in the stud. Values of such stresses were below 5.9 $\mathrm{MPa}$ for the body and bearing. For the comparison, under loading, the tie rod end by the force $F$ equal to $2000 \mathrm{~N}$, the von Mises stresses reached values of $211 \mathrm{MPa}$ for the stud, and $9.1 \mathrm{MPa}$ for the POM bearing [11]. This non-linear tendency may indicate a complex dependence of the von Mises stresses in the stud and bearing materials on the size of the ball joint, materials of its components, and the latter's geometric conditions of cooperation determined by the inclination angle [11].

The values of contact pressure $p$ between rotating steel ball stud and its POM bearing for the force $F=$ $300 \mathrm{~N}$ are shown in Fig. 11a. The maximum values of them were equal to $1.87 \mathrm{MPa}$.
The values of contact pressure $p$ between rotating steel ball stud and its POM bearing are shown for the force $F=200 \mathrm{~N}$ in Fig. 11b, for the $F=100 \mathrm{~N}$ in Fig. 11c and for $F=50 \mathrm{~N}$ in Fig. 11d, respectively. The maximum values of contact pressure relating to those force values were $1.24,0.63$ and $0.35 \mathrm{MPa}$, respectively.

The averaged values of contact pressure $p$ against the force $F$ are shown in Fig. 12. The averaged values of contact pressure $p$ were equal to $0.21 \mathrm{MPa}$ for the force $F$ value equal to $300 \mathrm{~N}$.

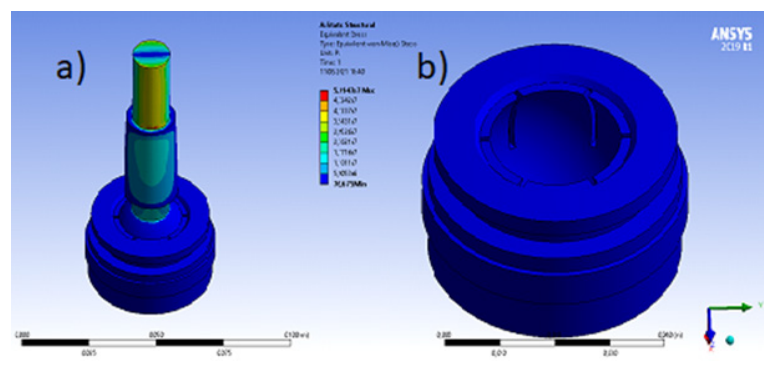

Fig. 10. von Mises stresses [MPa] in the model assembly for the tie rod end a) complete one, b) one without the stud, for the force

$$
F=300 \text { N }
$$

For the maximum sliding speed $v_{b}$ of the stud ball end relative to its bearing equal to $0.03 \mathrm{~m} / \mathrm{s}$, lithium grease UM185Li2 was modelled using the HerschelBulkley model, with its mentioned earlier parameters $\tau_{0}, m_{1}$, and $n$, the estimated initial grease thickness equal to $7 \mu \mathrm{m}$, and the assumed value equal to $0.1 \mathrm{~Pa} \cdot \mathrm{s}$ for the dynamic viscosity of its base oil, the equivalent dynamic viscosity $\eta_{e q}$ obtained from procedures described in [167] was equal to $0.129 \mathrm{~Pa} \cdot \mathrm{s}$.

The considerations on the effect of the lubricant presence on the contact pressure distributions in the contact zones between touching asperities of the stud ball end and its bearing, and pressure distribution in lubricant microclines surrounding such asperities were carried out for the following case chosen. The motion of the stud ball end relative to its bearing under constant rotational speed $2 \mathrm{rad} / \mathrm{s}$ and loading by constant force $F=300 \mathrm{~N}$, was modelled as the motion of a rigid plane relative to the rough surface with asperities modelled using evenly distributed and elasto-plastically deformed hemispheres. Such a motion was modelled with constant sliding speed $U=0.03 \mathrm{~m} / \mathrm{s}$ and under loading by force $F=300$ $\mathrm{N}$. During modelling of the motion, the load was carried out partly by modelled asperities being in contact and partly by hydrodynamic effects from grease microclines between these asperities. The obtained value of the average contact pressure in 

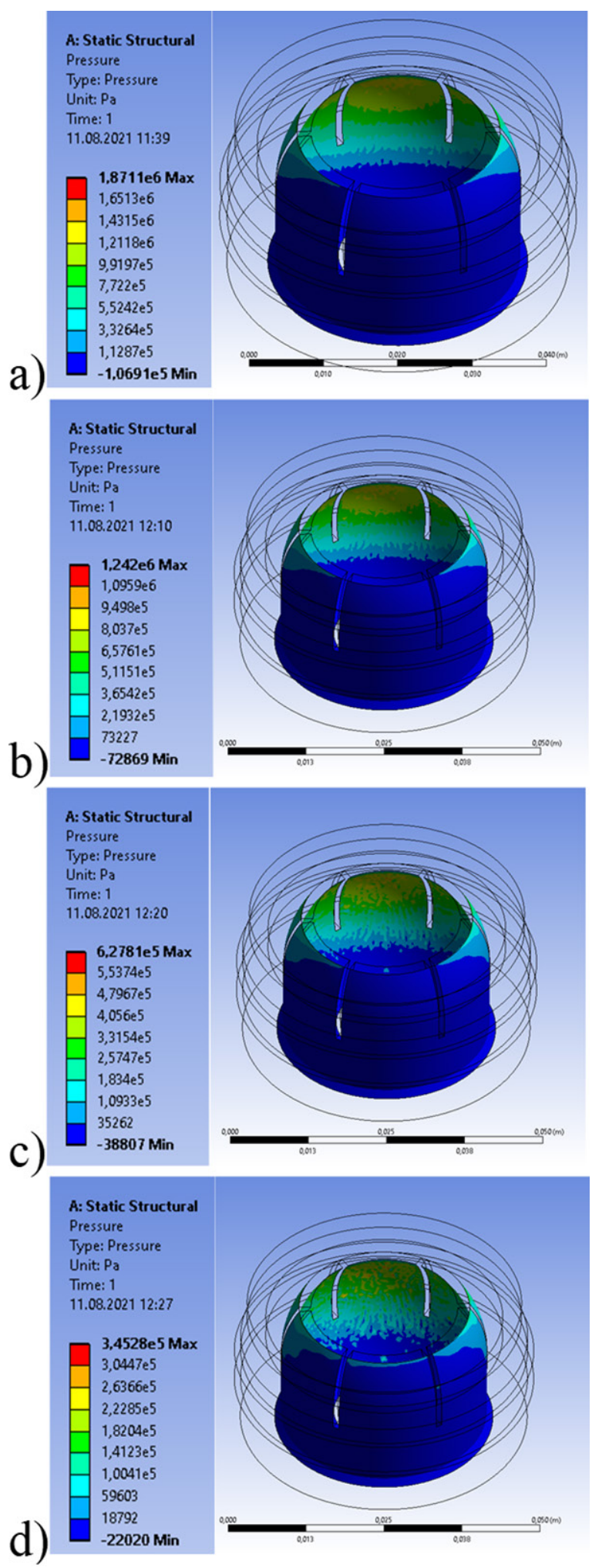

Fig. 11. The values of contact pressure $p[\mathrm{MPa}]$ between stud ball end and its POM bearing for the force: a) $F=300 \mathrm{~N}$; b) $F=200 \mathrm{~N}$; c) $F=100 \mathrm{~N}$; d) $F=50 \mathrm{~N}$ areas participating in carrying out load via plastically deformed asperities was equal to $150 \mathrm{MPa}$, and the average value of pressure in grease microclines was equal to $0.21 \mathrm{MPa}$.

The analysis of the squeezing process of lithium grease in a gap between the stud ball end and its bearing under the force $N=F=300 \mathrm{~N}$ loading the stud ball end was carried out for various initial eccentricity $e_{s q}$ in a range from 0 up to $7 \mu \mathrm{m}$. The obtained average value of the time derivative of the eccentricity ratio $\dot{\varepsilon}_{s q}$ reached values in a range from 0 to 0.028 , respectively. The course of the average pressure values in the squeezed grease layer in the gap between the stud ball end and its bearing under loading by force $F=300 \mathrm{~N}$ versus initial eccentricity ratio $\varepsilon_{s q}$ was presented in Fig. 13. Such values can reach $0.25 \mathrm{MPa}$, which was close to the average value of pressure in grease microclines when the stud ball end rotated relative to its bearing at the maximum sliding speed equal to $0.03 \mathrm{~m} / \mathrm{s}$ and was loaded by force $F=300 \mathrm{~N}$. It was visible that the increase of the initial eccentricity ratio $\varepsilon_{s q}$ resulted in a quick enhancement of average pressure values in the squeezed grease layer in the gap between the stud ball end and its bearing under loading the former by a given force $F$ value.

The measured outer diameters $D_{1}$ of the new and the worn ball end of the stud made of steel differ less than the resolution of the measurement with the passameter equal to $0.005 \mathrm{~mm}$. So, the wear $W_{1}$ of the ball end was omitted, as a small value. The maximal difference between measured inner diameters $D_{2}$ of new and worn POM bearings positioned in the bushing was equal to $0.4 \mathrm{~mm}$. The maximum wear $W_{2}$ of the POM bearing was of about $1.88 \cdot 10^{-7} \mathrm{~m}^{3}$. The obtained value of the wear intensity factor $k_{2}$ was equal to $1.38 \cdot 10^{-19} \mathrm{~m}^{4} \cdot \mathrm{N}^{-2}$ and thus the estimated value of the linear wear intensity $I_{h 2}$ for the POM bearing equal to $5.9 \cdot 10^{-9}$.

It should be noted that such values were obtained when the effect of lubrication occurrence in contact zone was included via an averaging of contact pressure values over the whole macroscopic contact area.

Using only the contact pressure occurred between plastically deformed asperities in the contact zone, the obtained value of the wear intensity factor $k_{2}$ was equal to $2.45 \cdot 10^{-20} \mathrm{~m}^{4} \cdot \mathrm{N}^{-2}$ and thus the estimated value of the linear wear intensity $I_{h 2}$ for the POM bearing equal to $5.5 \cdot 10^{-4}$, which was five orders higher compared to the former one.

For comparison, the results from tests on the pinon-flat tribotester [174] for the dry contact between POM pin and a plate made of cold rolled steel AISI 
$42 \mathrm{CrMo} 4$ ground to a roughness parameter $R a=$ $0.20 \mu \mathrm{m}$ were used. During the pin reciprocal motion with stroke equal to $15 \mathrm{~mm}$ relative to the fixed steel plate, the average sliding speed of $0.3 \mathrm{~m} \cdot \mathrm{s}^{-1}$ was almost eighteen-fold higher than the one for the stud-bearing contact. Under a normal load of $100 \mathrm{~N}$, the average contact pressure values were equal to 2 $\mathrm{MPa}$, respectively. Tests were conducted at room temperature; however, the temperature of the contact zone was not controlled.

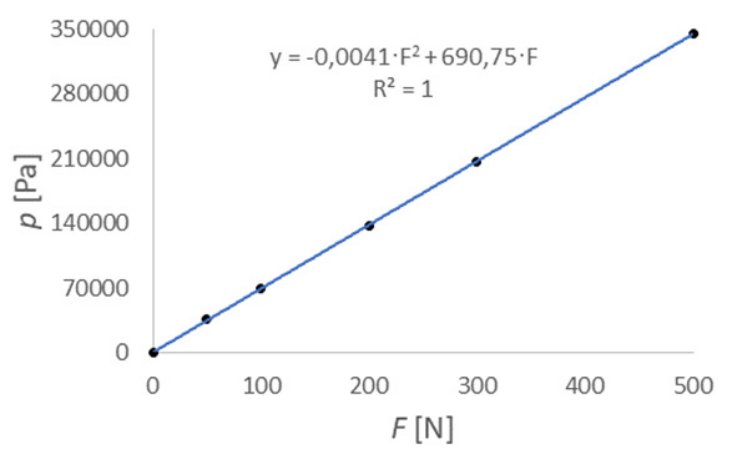

Fig. 12. The averaged values of contact pressure $p$ against the force $F$

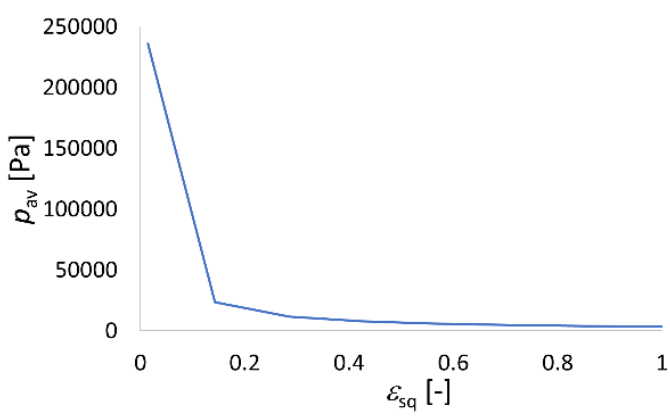

Fig. 13. The average pressure in the squeezed grease layer in gap between the stud ball end and its bearing under loading by force $F=300 \mathrm{~N}$, versus initial eccentricity ratio $\varepsilon_{s q}$

These values were almost ten-fold higher than that for the stud-bearing contact. The linear wear intensity for the POM, corresponding to the normal load of 100 $\mathrm{N}$, reached values $2.63 \cdot 10^{-10} \mathrm{MPa}$. Therefore, it was almost six orders lower than one for the POM bearing of the tie rod end, calculated using only the contact pressure occurring between plastically deformed asperities in the contact zone. When an effect of grease lubrication was included via an averaging of contact pressure values over the whole macroscopic contact area, the linear wear contact intensity for the POM pin was only 30 -fold lower than the one for the POM bearing of the tie rod end. It was because the sliding velocity, type, and shape of relative motion of mating surfaces highly affect the linear wear intensities in different contact zones.

Also, for the comparison, the results of the tests conducted using pin-on-disc tribotester [175] for the dry contact between POM-C pin and rotating disc made of $100 \mathrm{Cr}$ steel or AISI 3004 stainless steel were used. Such discs were polished to the roughness parameters $\mathrm{Ra}=0.1 \mu \mathrm{m}$. During tests, the constant sliding speed was equal to $0.05 \mathrm{~m} / \mathrm{s}$ and was threefold higher than the average one for the stud-bearing contact. The contact zone was loaded by the normal force $150 \mathrm{~N}$ corresponding to the contact pressure $1.5 \mathrm{MPa}$, which was seven-fold higher than that for the stud-bearing contact. The average temperature in contact zone was equal to $27{ }^{\circ} \mathrm{C}$ for the AISI 3004 stainless steel and to $30{ }^{\circ} \mathrm{C}$ for the $100 \mathrm{Cr}$ steel. The linear wear intensity for the POM, corresponding to the normal load of $150 \mathrm{~N}$, reached values 0.00585 for the case of $100 \mathrm{Cr}$ steel and 0.002925 for the case of AISI 3004 stainless steel. They were by the seven orders higher than the one for the POM bearing of the tie rod end when the effect of lubrication was included via an averaging of contact pressure values over the whole macroscopic contact area. When considering that only the contact pressure occurred between plastically deformed asperities in the contact zone, the linear wear intensity for the POM pin was ten-fold and five-fold higher, respectively, compared to the one for the POM bearing of the tie rod end.

It is visible that linear wear intensity in POMsteel contact can reach values from a wide range. The mentioned intensity depends on the contact pressure [174] and [176], sliding speed [175], temperature [175], humidity [177], operating conditions, particularly relative motion manner [174] to [177]. The studied POM bearing of the tie rod ends was lubricated by the lithium grease, although its amount quickly decreased during a millage of the vehicle operating in a severe environment. The temperature and humidity also varied in a wide range depending on the technical condition of the seal in the tie rod end assembly.

\section{CONCLUSIONS}

The wear rates of mating components of the ball joints were obtained experimentally. Wear of ball end was much lower than of the POM bearing in the case of the analysed stud.

Using finite element model of the stud the steering rod, mathematical equations describing kinematic dependencies for components the steering mechanism and assumed style of cornering, it was estimated value of the wear intensity factor $k$ equal $1.38 \cdot 10^{-19} \mathrm{~m}^{4} \cdot \mathrm{N}^{-2}$ 
for POM bearing of the stud. This corresponds to the linear wear intensity $I_{h}$ equal to $5.9 \cdot 10^{-9}$, which can vary in a wide range depending on the contact pressure, sliding speed, temperature, humidity, operating, and lubricating conditions for the tie rod end assembly. Obtained values of the wear intensity factor $k$ and the linear wear intensity $I_{h}$ could deviate from the actual values, as they were strongly affected by the method used for determining the average values of contact pressure in the contact zone between stud ball end and its bearing. A similar observation concerning the effect of the calculation method on the values of the mean contact pressure used in the calculation of was emphasized in [18].

Obtained averaged values of contact pressure between ball end and POM bearing almost linearly increased with force loading steering $\operatorname{rod} F$. The force $F$ value equal to $300 \mathrm{~N}$ caused the averaged values of contact pressure $p$ equal to $0.21 \mathrm{MPa}$. Under loading, the stud ball end by the same force $F$ values of contact pressure were close to these occurring during squeezing of the grease layer in the gap between the stud ball end and its bearing. Additionally, such values of contact pressure were close to these of pressure in areas of hydrodynamic effect of grease microclines when the similarly loaded stud ball end rotated relative to its bearing under maximal sliding speed equal to $0.03 \mathrm{~m} / \mathrm{s}$. Simultaneously, the contact pressure in contact zones between plastically deformed asperities reached value of $150 \mathrm{MPa}$.

\section{REFERENCES}

[1] Mondragon-Parra, E., Ambrose, G. (2016). Influence of Grease in Mechanical Efficiency of Constant Velocity Joints. SAE Technical Paper, 2016-01-1132, D0I:10.4271/2016-01-1132.

[2] Duffy, J.E. (2017). Modern Automotive Technology, 9th ed. The Goodheart-Willcox Company. Tinley Park, IL, USA.

[3] Chavan, P.M., Patnaik, M.M.M. (2014). Performance evaluation of passenger car tie rod using numerical and theoretical approach with different materials. International Journal of Research in Engineering and Technology, vol. 3, p. 92-100, Dol:10.15623/ijret.2014.0308015.

[4] Falah, A.H., Alfares, M.A., Elkholy, A.H. (2007). Failure investigation of a tie rod end of an automobile steering System. Engineering Failure Analysis, vol. 14, p. 895-902, D0I:10.1016/j.engfailanal.2006.11.045.

[5] Guiggiani, M. (2014). The Science of Vehicle Dynamics. 2nd ed. Springer, Netherlands, D0l:10.1007/978-94-017-8533-4.

[6] Manik, A.P., Chavan, D.S., Kavade, M.V., Umesh, S.G. (2013). FEA of tie rod of steering system of car. International Journal of Application or Innovation in Engineering \& Management, vol. 2, no. 5, p. 222-227.

[7] Kim, H., Seo, M., Bae, W. (2002). A study of the manufacturing of tie rod ends with casting/forging process. Journal of
Material Processing Technology, vol. 125, p. 471-476, D0I:10.1016/S0924-0136(02)00323-0.

[8] Essienubong, I.A., Ikechukwu, O., Ebunilo, P.O., Ememobong, E.I. (2016). Static analysis on a vehicle tie rod to determine the resulting buckling displacement. International Journal of Industrial and Manufacturing Systems Engineering, vol. 1, no. 1, p. 16-24, DOI: 10.11648/j.jjimse.20160101.13.

[9] Aravindaraj, E., Natrayan, L., Santhosh, M.S., Kumar, M.S. (2018). Design and analysis of connecting tie rod assembly for automotive application. Journal of Engineering Sciences, vol. 5, p. D15-D20, D0I:10.21272/jes.2018.5(2).d3.

[10] Natrayan, L., Aravindaraj, E., Santhosh, M.S., Kumar, S. (2019). Analysis and optimization of connecting tie rod assembly in Agriculture application. Acta Mechanica Malaysia, vol. 2, no. 1, p. 6-10, DOl:10.26480/amm.01.2019.06.10.

[11] Ozsoy, M., Pehlivan M. K. (2015). Computer aided structral analysis of a tie rod end. Acta Physica Polonica A, vol. 128, no. 2B, p. B488-B490, D0l:10.12693/APhysPolA.128.B-488.

[12] Patil, M.A., Chavan, D.S., Kavade, M.V., Ghorpade, U.S., (2013). FEA of tie rod of steering system of car. International Journal of Application or Innovation in Engineering \& Management, vol. 2, no. 5, p. 222-227.

[13] Senniappan, M., More, R., Bhide, S., Gowda, S. (2016). Optimization of commercial vehicle's steering tie rod arm design based on strain life approach. SAE Technical Paper, 2016-01-0381, D0I:10.4271/2016-01-0381.

[14] Ćatić, D., Jeremić, B., Djordjević, Z., Miloradović, N. (2011). Criticality analysis of the elements of the light commercial vehicle steering tie-rod joint. Strojniški vestnik - Journal of Mechanical Engineering, vol. 57, no. 6, p. 495-502, DOI:10.5545/sv-jme.2010.077.

[15] Park, Y.-C., Baek, S.-K., Seo, B.-K., Kim, J.-K., Lee, K.-H. (2014). Lightweight design of an outer tie rod for an electrical vehicle. Journal of Applied Mathematics, vol. 2014, 942645, DOl:10.1155/2014/942645.

[16] Meng, H.C., Ludema, K.C. (1995). Wear models and predictive equations: their form and content. Wear, vol. 181-183, p. 443-457, DOI:10.1016/0043-1648(95)90158-2.

[17] Szczerek, M. (1999). Wear description from the appearance and detection point of view. Scientific Problems of Machines Operation and Maintenance, vol. 34, no. 4, p. 659-675.

[18] Zwierzycki, W. (1990). The Issues of a Priori Evaluation of the Durability of Sliding Friction Nodes. Poznan University of Technology, Poznan.

[19] Zwierzycki, W., (1998). Forecasting the Reliability of Wearing Parts of Machines. ITE, Radom.

[20] Wozniak, M., Siczek, K., Ozuna, G., Jozwiak, P. (2018). Investigations on wear and friction in the SI engine valvetrain. Combustion Engines, vol. 175, no. 4, p. 53-64, D0l:10.19206/ CE-2018-408.

[21] Zwierzycki, W., Gradkowski, M. (2000). Physical Basis for the Selection of Materials for Frictionally Mating Machine Elements. ITE, Radom.

[22] Rochatka, T., Stachowiak, A., Zwierzycki, W. (2006). Wear of chosen material combinations in food fats (in the combination: three rolls - cone). Agricultural Engineering, vol. 10, no. 7(82), p. 377-382. 
[23] Burdzik, R., Folega, P., Lazarz, B., Stanik, Z., Warczek, J. (2012). Analysis of the Impact of Surface Layer Parameters on Wear Intensity of Friction Pairs. Archives of Metallurgy and Materials, vol. 57, p. 987-993, D0l:10.2478/v10172-0120110-8.

[24] Vyshnevskyi, O.A., Davydov, A.S. (2015). Modeling the linear wear intensity with consideration of hardness and average pressure to friction surface. Information Processing Systems, vol. 4, no. 129, pp. 64-67.

[25] Wozniak, M., Siczek, K., Kubiak, P., Jozwiak, P., Siczek, K. (2018). Researches on tie rod ends lubricated by grease with $\mathrm{TiO}_{2}$ and $\mathrm{ZrO}_{2}$ nanoparticles. Journal of Physics: Conference Series, vol. 1033, no. 1, 012006, D0l:10.1088/17426596/1033/1/012006.

[26] Muscoplat, R. (2018). Tie rod - What is a tie rod? Rick's Free Auto Repair Advice, from https://ricksfreeautorepairadvice. com/tie-rod-tie-rod/, accessed on 221-12-31.

[27] Hegedüs, F., Bécsi, T., Aradi, S., Gáspár, P. (2019). Motion planning for highly automated road vehicles with a hybrid approach using nonlinear optimization and artificial neural networks. Strojniški vestnik - Journal of Mechanical Engineering, vol. 65, no. 3, p. 148-160, D0l:10.5545/svjme.2018.5802.

[28] Subirats, P., Goyat, Y., Jacob, B., Violette, E. (2016). A new road safety indicator based on vehicle trajectory analysis. Transportation Research Procedia, vol. 14, p. 4267-4276, DOI:10.1016/j.trpro.2016.05.398.

[29] Houenou, A., Bonnifait, P., Cherfaoui, V., Wen, Y. (2013). Vehicle Trajectory Prediction based on Motion Model and Maneuver Recognition. IEEE/RSJ International Conference on Intelligent Robots and Systems, Tokyo, p. 4363-4369, DOI:10.1109/IROS.2013.6696982.

[30] Aykent, B., Merienne, F., Guillet, C., Paillot, D., Kemeny, A. (2014). Motion sickness evaluation and comparison for a static driving simulator and a dynamic driving simulator. Journal of Automobile Engineering, vol. 228, no. 7, p. 818829, Dol:10.1177/0954407013516101.

[31] Michael-Grigoriou, D., Kleanthous, M., Savva, M., Christodoulou, S., Pampaka, M., Gregoriades, A. (2014). Impact of immersion and realism in driving simulator studies. International Journal of Interdisciplinary Telecommunications and Networking, vol. 6, no. 1, p. 10-25, D0l:10.4018/ ijitn.2014010102.

[32] Dziuda, L., Biernacki, M., Baran, P., Trszczynski, 0. (2014). The effects of simulator fog and motion on simulator sickness in a driving simulator and the duration of after-effects. Applied Ergonomics, vol. 45, no. 3, p. 406-412, D0l:10.1016/j. aperg0.2013.05.003.

[33] Lefèvre, S., Vasquez, D., Laugier, C. (2014). A survey on motion prediction and risk assessment for intelligent vehicles. Robomech Journal, vol. 1, p. 1, D0l:10.1186/s40648-0140001-z.

[34] Xu, J., Luo, X., Shao, Y.M. (2018). Vehicle trajectory at curved sections of two-lane mountain roads: a field study under natural driving conditions. European Transport Research Review, vol. 10, p. 12, D0l:10.1007/s12544-018-0284-x.
[35] Lakkad, S., (2004). Modeling and Simulation of Steering Systems for Autonomous Vehicles. PhD Thesis. Florida State University, USA.

[36] Chebly, A. (2017). Trajectory planning and tracking for autonomous vehicles navigation. Automatic Control Engineering. PhD Thesis. Université de Technologie de Compiègne, D2392.

[37] Wang, R., Li, G., Zhang, S., Liu, L., Zhang, X., Yin, Y. (2021). Trajectory tracking control in real-time of dual-motor-driven driverless racing car based on optimal control theory and fuzzy logic method. Complexity, vol. 2021, p. 5549776, DOl:10.1155/2021/5549776.

[38] Li, B., Du, H., Li, W., Zhang, B. (2018). Dynamically integrated spatiotemporal-based trajectory planning and control for autonomous vehicles. Faculty of Engineering and Information Sciences - Papers: Part B, p. 2124. .

[39] Ding, W., Shen, S., (2019). Online vehicle trajectory prediction using policy anticipation network and optimization-based context reasoning. International Conference on Robotics and Automation, p. 9610-9616, D0I:10.1109/ICRA.2019.8793568.

[40] Kim, B.D., Kang, C.M., Kim, J., Lee, S.H., Chung, C.C., Choi, J.W. (2018). Probabilistic vehicle trajectory prediction over occupancy grid map via recurrent neural network. IEEE 20th International Conference on Intelligent Transportation Systems, p. 399-404, D0I:10.1109/ITSC.2017.8317943.

[41] Li, B., Du, H., Li, W. (2016). Trajectory control for autonomous electric vehicles with in-wheel motors based on a dynamics model approach. Institution of Engineering and Technology (IET) Intelligent Transport Systems, vol. 10, p. 318-330. https://doi.org/10.1049/iet-its.2015.0159.

[42] Zheng, H., Yang, S. (2019). A trajectory tracking control strategy of 4WIS/4WID electric vehicle with adaptation of driving conditions. Applied Science, vol. 9, p. 168, DOI:10.3390/app9010168.

[43] Jiang, H., Zhou, J., Li, A., Zhou, X., Ma, S. (2019). Human-like trapezoidal steering angle model on two-lane urban curves. International Journal of Advanced Robotic Systems, vol. July 2019, Dol:10.1177/1729881419867614.

[44] Ossa, E.A., Palacio, C.C., Paniagua M. (2011) Failure analysis of a car suspension system ball joint. Engineering Failure Analysis, vol. 18, no. 5, p. 1388-1394, D0l:10.1016/j. engfailanal.2011.03.013.

[45] Bayrak, M., Ozturk, F., Demirezen, M., Evis, Z. (2007). Analysis of tempering treatment on material properties of DIN $41 \mathrm{Cr} 4$ and DIN 42CrMo4 steels. Journal of Materials Engineering and Performance, vol. 16, no. 5, p. 597-600, Dol:10.1007/ s11665-007-9043-1.

[46] Bol'shakov, V.I., Laukhin, D.V., Sukhomlin, G.D., Kuksenko, V.I. (2004). Effect of heat treatment on formation of acicular ferrite and on the properties of low carbon microalloyed steels 10G2FB and 09G2S. Metal Science and Heat Treatment, vol. 46, no. 11-12, p. 545-50, D0l:10.1007/s11041-005-0016-4.

[47] Murakami, Y. (2002). Metal fatigue: effects of small defects and non-metallic inclusions. Elsevier, Kidlington, Oxfordshire.

[48] Alsaran, A., Karakan, M., Celik, A. (2002). The investigation of mechanical properties of ion-nitrided AISI 5140 low-alloy steel. Materials Characterization, vol. 48, no. 4, p. 323-327, DOl:10.1016/S1044-5803(02)00275-9. 
[49] Rayu, Y.I., Kang, D.O., Heo, S.J., Yim, H.J., Jeon, J.I. (2010). Development of analytical process to reduce side load in strut-type suspension. Journal of Mechanical Science and Technology, vol. 24, no. 1, p. 351-356, D0l:10.1007/s12206009-1103-z.

[50] Lee, K.-H., Kim, J.K., Kim, Y.J., Yang, W.H., Park, Y.C. (2011). Structural design of an outer tie rod for a passenger car. International Journal of Automotive Technology, vol. 12, 375, D0I:10.1007/s12239-011-0044-6.

[51] Miettinen, J., Andersson, P. (2000). Acoustic emission of rolling bearings lubricated with contaminated grease. Tribology International, vol. 33, no. 11, p. 777-787, DOI:10.1016/S0301-679X(00)00124-9.

[52] Sharma, R.B., Parey, A. (2019). Modelling of acoustic emission generated in rolling element bearing. Applied Acoustics, vol. 144, p. 96-112, Dol:10.1016/j.apacoust.2017.07.015.

[53] Patil, A.P., Mishra, B.K., Harsha. S.P. (2020). Vibration based modelling of acoustic emission of rolling element bearings. Journal of Sound and Vibration, vol. 468, p. 115117, Dol:10.1016/j.jsv.2019.115117.

[54] Wang, Y.L., Wang, W.Z., Zhang, S.G. (2018). Effects of raceway surface roughness in an angular contact ball bearing. Mechanism and Machine Theory, vol. 121, p. 198-212, D0I:10.1016/j.mechmachtheory.2017.10.016.

[55] Liu, J., Xu, Y., Pan, G. (2021). A combined acoustic and dynamic model of a defective ball bearing. Journal of Sound and Vibration, vol. 501, p. 116029, D0l:10.1016/j. jsv.2021.116029.

[56] Masjedi, M., Khonsari, M.M. (2015). An engineering approach for rapid evaluation of traction coefficient and wear in mixed EHL. Tribology International, vol. 92, p. 184-190, DOI:10.1016/j.triboint.2015.05.013.

[57] Tong, V.C., Hong, S.W. (2018). Improved formulation for running torque in angular contact ball bearings. International Journal of Precision Engineering and Manufacturing, vol. 19, p. 47-56, DOI:10.1007/s12541-018-0006-2.

[58] Marques, F., Flores, P., Claro, J.C., Lankarani, H. (2018). Modeling and analysis of friction including rolling effects in multibody dynamics: A review. Multibody System Dynamics, vol. 45, no. 4, p. 223-244, Dol:10.1007/s11044-018-096406.

[59] Dykha, A., Sorokatyi, R., Makovkin, O., Babak, O. (2017). Calculation-experimental modeling of wear of cylindrical sliding bearings. Eastern-European Journal of Enterprise Technologies, vol. 5, no. 1, p. 51-59, D0l:10.15587/1729. 4061.2017.109638.

[60] Dykha, A., Marchenko, D. (2018). Prediction the wear of sliding bearings. International Journal of Engineering \& Technology, vol. 7, no. 2.23, p. 4-8, Dol:10.14419/ijet.v7i2.23.11872.

[61] Rezaei, A., Ost, W., Van Paepegem, W., De Baets, P., Degrieck, J. (2011). Experimental study and numerical simulation of the large-scale testing of polymeric composite journal bearings: Three-dimensional and dynamic modelling. Wear, vol. 270, no. 7-8, p. 431-438, D0l:10.1016/j.wear.2010.11.005.

[62] Rezaei, A., Ost, W., Van Paepegem, W., De Baets, P., Degrieck, J. (2012). A study on the effect of the clearance on the contact stresses and kinematics of polymeric composite journal bearings under reciprocating sliding conditions.
Tribology International, vol. 48, p. 8-14, D0l:10.1016/j. triboint.2011.06.031.

[63] Rezaei, A., Van Paepegem, W., De Baets, P., Ost, W., Degrieck, J. (2012). Adaptive finite element simulation of wear evolution in radial sliding bearing. Wear, vol. 296, no. 1-2, p. 660-671, Dol:10.1016/j.wear.2012.08.013.

[64] Sorokatyi, R.V. (2003). Solution of the problem of wear of a fine elastic layer with a rigid bearing mounted on a rigid shaft using the method of triboelements. Journal of Friction and Wear, vol. 24, no. 1, p. 35-41.

[65] Sorokatyi, R.V. (2003). Evaluation of efficiency of sliding bearings during reciprocation. Journal of Friction and Wear, vol. 24, no. 2, p. 136-143.

[66] Chernets, M.V., Zhydyk, V.B., Chernets', Yu.M. (2014). Accuracy of evaluation of the service life of a plain bearing according to the generalized cumulative model of wear. Materials Science, vol. 50, p. 39-45, D0l:10.1007/s11003-014-9689-4.

[67] Chernets, M., Chernets, Ju. (2015). Generalized method for calculating the durability of sliding bearings with technological out-of-roundness of details. Proceedings of the Institution of Mechanical Engineers, Part J: Journal of Engineering Tribology, vol. 229, no. 2, p. 216-226, DOl:10.1177/1350650114554242.

[68] Chernets, M.V. (2015). Prediction of the life of a sliding bearing based on a cumulative wear model taking into account the lobing of the shaft contour. Journal of Friction and Wear, vol. 36, p. 163-169, D0l:10.3103/S1068366615020038.

[69] Sep, J., Galda, L., Oliwa, R., Dudek, K. (2020). Surface layer analysis of helical grooved journal bearings after abrasive tests. Wear, vol. 448-449, p. 203233, D0I:10.1016/j. wear.2020.203233.

[70] König, F., Marheineke, J., Jacobs, G., Sous, C., Zuo, M.J., Tian, Z. (2021). Data-driven wear monitoring for sliding bearings using acoustic emission signals and long short-term memory neural networks. Wear, vol. 476, p. 203616, D0I:10.1016/j. wear.2021.203616.

[71] Ejtehadi, M.H., Klaus, H., Sommer, S., Haensel, H., Scholten, J. (2011). Running-in phase of spherical chassis joints - identification of the main influence parameter and implementation in a wear simulation tool. International Journal of Advanced Manufacturing Technology, vol. 55, no. 9-12, 983-995, D0I:10.1007/s00170-010-3136-y.

[72] Kadhim, N.A., Abdullah, S., Ariffin A. (2012). Effective strain damage model associated with finite element modelling and experimental validation. International Journal of Fatigue, vol. 36, no. 1, p. 194-205, D0I:10.1016/j.ijfatigue.2011.07.012.

[73] Mao, J., Luo, Y., Liu, J. (2014). Dynamics performance and abrasive wear of the automotive drive shaft. Advances in Mechanical Engineering, vol. 6, p. 713824-713824, DOI:10.1155/2014/713824.

[74] Scholten, J., Haensel, H., Krekeler, N., Fuchs, H., Stenke, R., Ejtehadi, M.H. (2010). Modellierung des Einflusses der Verschleissverteilung auf die Beanspruchung von Fachwerksgelenken. 'Inhalt' Materials Testing, vol. 52, no. 7-8, p. 463-469, DOI:10.3139/120.010072.

[75] Watrin, J., Makich, H., Haddag, B., Nouari, M., Grandjean, X. (2017). Analytical modelling of the ball pin and plastic socket contact in a ball joint. Congrès français de mécanique, Lille. 
[76] Wu, S., Hung, J., Shu, C. (2003). The computer simulation of wear behavior appearing in total hip prosthesis. Computer Methods and Programs in Biomedicine, vol. 70, no. 1, p. 8191, D0l:10.1016/s0169-2607(01)00199-7.

[77] Pietrabessa, R., Raimondi, M., Di Martino, E. (1998). Wear of polyethylenecups in total hip arthroplasty: a parametric mathematical model. Medical Engineering \& Physics, vol. 20, no. 3, p. 199-210, D0l:10.1016/s1350-4533(98)00004-6.

[78] Maxian, T., Brown, T.D., Pederson, R.D., Callaghan, J.J. (1996). A sliding distance coupled finite element formulation for polyethylene wear in total hip arthroplasty. Journal of Biomechanics, vol. 29, no. 5, p. 687-692, D0l:10.1016/00219290(95)00125-5.

[79] Chernets, M., Opielak, M., Kornienko, A., Radko, O. (2021). Predictive estimation of sliding bearing load-carrying capacity and tribological durability. Strojniški vestnik - Journal of Mechanical Engineering, vol. 67, no. 7-8, p. 363-368, DOI:10.5545/sv-jme.2021.7139.

[80] Mukras, S.M.S. (2020). Computer Simulation/Prediction of Wear in Mechanical Components. Advances in Tribology, vol. 2020, p. 8867351, DOl:10.1155/2020/8867351.

[81] Mukras, S., Kim, N.H., Sawyer, W.G., Jackson, D.B., Bergquist, L.W. (2009). Numerical integration schemes and parallel computation for wear prediction using finite element method. Wear, vol. 266, no. 7, p. 822-831, D0I:10.1016/j. wear.2008.12.016.

[82] Mukras, S., Kim, N.H., Mauntler, N.A., Schmitz, T.L., Sawyer, W.G. (2010). Analysis of planar multibody systems with revolute joint wear. Wear, vol. 268, no. 5-6, pp. 643-652, D0l:10.1016/j.wear.2009.10.014.

[83] Mukras, S., Kim, N.H., Mauntler, N.A., Schmitz, T.L., Sawyer, W.G. (2010). Comparison between elastic foundation and contact force models in wear analysis of planar multibody system. Journal of Tribology, vol. 132, no. 3, p. 031604, DOl:10.1115/1.4001786.

[84] Kim, N.H., Won, D., Burris, D., Holtkamp, B., Gessel, G.R., Swanson, P., Sawyer, W.G. (2005). Finite element analysis and experiments of metal/metal wear in oscillatory contacts. Wear, vol. 258, no. 11-12, p. 1787-1793, D0I:10.1016/j. wear.2004.12.014.

[85] Uguz, A., Oka, S. (2004). Finite element modeling of ball joints under dynamic loading. Materials Testing, vol. 46, no. 10, p. 506-512, DOI:10.3139/120.100618.

[86] Martins, R.C., Moura, P.S. and Seabra, J.0. (2006). MoS2/Ti Low-Friction Coating for Gears. Tribology International, vol. 39, no. 12, p. 1686-1697, D0l:10.1016/j.triboint.2006.02.065.

[87] Bruno, G., Fanara, C., Guglielmetti, F. and Malard, B. (2006). Characterization and Residual Stress Analysis of WearResistant Mo Thermal Spray-Coated Steel Gear Wheels. Surface and Coatings Technology, vol. 200, no. 14, p. 42664276, D0I:10.1016/j.surfcoat.2005.01.103.

[88] Yonekura, D., Chittenden, R.J. and Dearnley, P.A. (2005). Wear mechanisms of steel roller bearings protected by thin, hard and low friction coatings. Wear, vol. 259, no. 1, p. 779-788, D0l:10.1016/j.wear.2004.12.008.

[89] Liu, C., Bi, Q., Matthews, A. (2003). Tribological and electrochemical performance of PVD tin coatings on the femoral head of Ti6Al4V articial hip joints. Surface and
Coatings Technology, vol. 163-164, no. 7, p. 597-604, D0l:10.1016/S0257-8972(02)00630-8.

[90] Diao, D., Kandori, A. (2006). Finite element analysis of the effect of interfacial roughness and adhesion strength onthe local delamination of hard coating under sliding contact. Tribology International, vol. 39, no. 9, p. 849-855, D0I:10.1016/j.triboint.2005.07.037.

[91] Kanber, B., Demirhan, N. (2013). Finite element analysis of frictional contact of elastic solids with thin and moderately thick coatings. Turkish Journal of Engineering and Environmental Sciences, vol. 37, no. 2, p. 162-177, DOl:10.3906/muh-1205-14.

[92] Syed, Z., Mohamed, H., Mohammed, M.A.H. (2014). Evaluation of contact stress distribution of hip joint model using finite element method. International Journal of Engineering Research \& Technology, vol. 3, no. 6, p. 16031610.

[93] Cilingir, A.C., Ucar, V., Udofia, I.J., Jinet, Z.M. (2008). Biphasic finite element modelling of contact mechanics of hemiarthoplasty of human hip joint. Part II: Polycarbonate urethane on cartilage contact. Journal of Trends Biomaterial Artificial Organs, vol. 22, no. 2, p. 65-72.

[94] Shinde, J., Kadam, S., Patil, A., Pandit, S. (2016). Design modification and analysis of suspension ball joint using finite element analysis. International Journal of Innovative Research in Science, Engineering and Technology, vol. 5, no. 7, p. 12797-12804, DOI:10.15680/IJIRSET.2016.0507135.

[95] Shinde, J., Kadam, S. (2016). Design of suspension ball joint using FEA and experimental method. International Research Journal of Engineering and Technology, vol. 3, no. 7, p. 18531858.

[96] Jang, B.H., Lee, K.H. (2014). Analysis and design of a ball joint, considering manufacturing process. Proceedings of the Institution of Mechanical Engineers, Part C: The Journal of Mechanical Engineering Science, vol. 228, no. 1, p. 146-151, DOl:10.1177/0954406213497317.

[97] Hugnell, A., Andersson, S. (1994) Simulating follower wear in a cam-follower contact. Wear, vol. 179, no. 1-2, p. 101-107, Dol:10.1016/0043-1648(94)90226-7.

[98] Hugnell, A., Björklund, S., Andersson, S. (1996). Simulation of the mild wear in a cam-follower contact with follower rotation. Wear, vol. 199, no. 2, p. 202-210, D0l:10.1016/00431648(96)06920-7.

[99] Flodin, A., Andersson, S. (1997). Simulation of mild wear in spur gears. Wear, vol. 207, no. 1-2, p. 16-23, D0l:10.1016/ s0043-1648(96)07467-4.

[100]Flodin, A., Andersson, S. (1999). Wear simulation of spur gears. Tribotest, vol. 5, no. 3, p. 225-249, D0l:10.1002/ tt.3020050303.

[101]Flodin, A. (2000). Wear of Spur and Helical Gears. Royal Institute of Technology, Stockholm.

[102]Flodin, A., Andersson, S. (2000). Simulation of mild wear in helical gears. Wear, vol. 241, no. 2, p. 123-128, D0l:10.1016/ s0043-1648(00)00384-7.

[103]Põdra, P., Andersson, S. (1997). Wear simulation with the Winkler surface model. Wear, vol. 207, no. 1, p. 79-85, DOl:10.1016/S0043-1648(96)07468-6. 
[104]Sfantos, G.K., Aliabadi, M.H. (2007). A boundary element formulation for three-dimensional sliding wear simulation. Wear, vol. 262, no. 5, pp. 672-683, D0l:10.1016/j. wear.2006.08.008.

[105]Sfantos, G.K., Aliabadi, M.H. (2006). Wear simulation using an incremental sliding boundary element method. Wear, vol. 260, no. 9-10, p. 1119-1128, D0l:10.1016/j. wear.2005.07.020.

[106]Rodríguez-Tembleque, L., Abascal, R., Abascal, R., Aliabadi, M.H. (2010). A boundary element formulation for wear modeling on $3 d$ contact and rolling-contact problems. International Journal of Solids and Structures, vol. 47, no. 1819, p. 2600-2612, D0l:10.1016/j.ijsolstr.2010.05.021.

[107]Wang, C., Schipper, D.J. (2020). A numerical-analytical approach to determining the real contact area of rough surface contact. Tribology - Materials, Surfaces \& Interfaces, vol. 14, no. 3, p. 166-176, D0l:10.1080/17515831.2020.172 0382.

[108] Liew, H.V., Lim, T.C. (2005). Analysis of time-varying rolling element bearing characteristics. Journal of Sound and Vibration, vol. 283, no. 3-5, p. 1163-1179, D0l:10.1016/j. jsv.2004.06.022.

[109]Liu, F., Wu, W., Hu, J., Yuan, S. (2019). Design of multi-range hydro-mechanical transmission using modular method. Mechanical Systems and Signal Processing, vol. 126, p. 1-20. D0I:10.1016/j.ymssp.2019.01.061.

[110] Liu J., Tang C., Shao Y. (2019). An innovative dynamic model for vibration analysis of a flexible roller bearing. Mechanism and Machine Theory, vol. 135, p. 27-39, D0l:10.1016/j. mechmachtheory.2019.01.027.

[111] Ascubal Ascurol. (2021). Rod ends with roller bearing, from https://www.directindustry.com/industrial-manufacturer/ rod-end-roller-bearing-249195.html, accessed on 2021-1231.

[112] Kipp.com (2021). K0716 Rod ends with ball bearing external thread, from https://www.kipp.com/gb/en/Products/ Operating-parts-standard-elements/Joints/K0716-Rod-endswith-ball-bearing-and-external-thread.html, accessed on 2021-12-31.

[113]Liu, J., Tang, C., Wu, H., Xu, Z., Wang, L. (2019). An analytical calculation method of the load distribution and stiffness of an angular contact ball bearing. Mechanism and Machine Theory, vol. 142, p. 103597, D0l:10.1016/j. mechmachtheory.2019.103597.

[114] Palmgren, A. (1959). Ball and Roller Bearing Engineering. SKF Industries Inc., Philadelphia, USA.

[115] Houpert, L. (1997). A uniform analytical approach for ball and roller bearings calculations. Journal of Tribology, vol. 119, no. 4, p. 851-858, Dol:10.1115/1.2833896.

[116] Hernot, X., Sartor, M., Guillot, J. (2000). Calculation of the stiffness matrix of angular contact ball bearings by using the analytical approach. Journal of Mechanical Design, vol. 122, no. 1, p. 83-90, D0I:10.1115/1.533548.

[117] Harris, T.A. (2001). Rolling Bearing Analysis. 4th ed., John Wiley \& Sons, New York.

[118]Spiewak, S.A., Nickel, T. (2001). Vibration based preload estimation in machine tool spindles. International Journal of
Machine Tools and Manufacture, vol. 41, no. 4, p. 567-588, DOI:10.1016/S0890-6955(00)00081-X.

[119] Hwang, Y.K., Lee, C.M. (2009). Development of automatic variable preload device for spindle bearing by using centrifugal force. International Journal of Machine Tools and Manufacture, vol. 49, no. 10, p. 781-787, D0l:10.1016/j. ijmachtools.2009.04.002.

[120]Chen, J.S., Chen, K.W. (2005). Bearing load analysis and control of a motorized high speed spindle. International Journal of Machine Tools and Manufacture, vol. 45, no. 1213, p. 1487-1493, D0l:10.1016/j.ijmachtools.2005.01.024.

[121] Jones, A.B. (1960). A general theory for elastically constrained ball and radial roller bearings under arbitrary load and speed conditions. Journal of Basic Engineering, vol. 82, no. 2, p. 309-320, DOI:10.1115/1.3662587.

[122]Li, X., Yu, K., Ma, H., Cao, L., Luo, Z., Li, H., Che, L. (2018). Analysis of varying contact angles and load distributions in defective angular contact ball bearing. Engineering Failure Analysis, vol. 91, p. 449-464, D0l:10.1016/j. engfailanal.2018.04.050.

[123]Fang, B., Zhang, J., Hong, J. (2017). Quick calculation method and contact angle analysis for high-speed angular contact ball bearing under combined loads. Journal of Xi'an Jiaotong University, vol. 51, no. 6, p. 115-121, D0l:10.7652/ xjtuxb201706019.

[124]Tang, Y.B., Gao, D.P., Luo, G.H. (2006). Research of aeroengine high-speed ball bearing. Journal of Aerospace Power, vol. 21, p. 354-360.

[125]Feng, J., Sun, Z., Li, H. (2016). Investigation of the stiffness and displacement of multiple combinations of angular contact ball bearings. Journal of Vibrational Measurement \& Diagnosis, vol. 36, no. 4, p. 784-789, D0l:10.16450/j.cnki. issn.1004-6801.2016.04.027.

[126]Noel, D., Ritou, M., Furet, B., Le Loch, S. (2013). Complete analytical expression of the stiffness matrix of angular contact ball bearings. Journal of Tribology, vol. 135, no. 4, p. 041101 , DOI:10.1115/1.4024109.

[127]Sheng, X., Li, B., Wu, Z., Li, H. (2014). Calculation of ball bearing speed-varying stiffness. Mechanism and Machine Theory, vol. 81, p. 166-180, D0I:10.1016/J.mechmachtheory.2014.07.003.

[128]Zhang, J., Fang, B., Hong, J., Wan, S., Zhu, Y. (2017). A general model for preload calculation and stiffness analysis for combined angular contact ball bearings. Journal of Sound and Vibration, vol. 411, p. 435-449, D0I:10.1016/j. jsv.2017.09.019.

[129]Zhang, J., Fang, B., Zhu, Y., Hong, J. (2017). A comparative study and stiffness analysis of angular contact ball bearings under different preload mechanisms. Mechanism and Machine Theory, vol. 115, p. 1-17, Dol:10.1016/j. mechmachtheory.2017.03.012.

[130]Fang, B., Zhang, J., Yan, K., Hong, J., Wang, M.Y. (2019). A comprehensive study on the speed-varying stiffness of ball bearing under different load conditions. Mechanism and Machine Theory, vol. 136, p. 1-13, handle/1783.1/96320.

[131]Cheng, Q., Qi, B., Liu, Z., Zhang, C., Xue, D. (2019). An accuracy degradation analysis of ball screw mechanism considering time-varying motion and loading working 
conditions. Mechanism and Machine Theory, vol. 134, p. 1-23, D0I:10.1016/j.mechmachtheory.2018.12.024.

[132]Jedrzejewski, J., Kwasny, W. (2010). Modelling of angular contact ball bearings and axial displacements for highspeed spindles. CIRP Annals, vol. 59, no. 1, p. 377-382, DOI:10.1016/j.cirp.2010.03.026.

[133]Zhang, J., Fang, B., Hong, J., Zhu, Y. (2017). Effect of preload on ball-raceway contact state and fatigue life of angular contact ball bearing. Tribology International, vol. 114, p. 365372, D0l:10.1016/j.triboint.2017.04.029.

[134]Ren, X., Zhai, J., Ren, G. (2017). Calculation of radial load distribution on ball and roller bearings with positive, negative and zero clearance. International Journal of Mechanical Sciences, vol. 131 p. 1-7, handle/181551/8818.

[135]Guo, Y., Parker, R.G. (2012). Stiffness matrix calculation of rolling element bearings using a finite element/contact mechanics model. Mechanism and Machine Theory, vol. 51, p. 32-45, DOI:10.1016/j.mechmachtheory.2011.12.006.

[136]Daidié, A., Chaib, Z., Ghosn, A. (2008). 3D simplified finite elements analysis of load and contact angle in a slewing ball bearing. Journal of Mechanical Design, vol. 130, no. 8, p. 082601, DOl:10.1115/1.2918915.

[137]Wang, H., Han, Q., Zhou, D. (2017). Nonlinear dynamic modeling of rotor system supported by angular contact ball bearings. Mechanical Systems and Signal Processing, vol. 85, p. 16-40, D0l:10.1016/J.ymssp.2016.07.049.

[138]Ansys Contact Technology Guide. Ansys Release 2020 R1, from https://d.shikey.com/down/Ansys.Products.2020. R1.x64/install_docs/Ansys.Products.PDF.Docs.2020R1/ readme.html, accessed on 2021-12-31.

[139]Shinohara, K. (2006). Thermoplastic Resin Composition Containing Mesoporous Powders Absorbed with Lubricating Oils, Patent WO 2006057974 A1.

[140]Rabinowicz, E. (1995). Friction and Wear of Materials. WileyInterscience.

[141]Zhang, B., Quiñonez, A., Venner, C. (2020). Effect of material anisotropy on rolling contact fatigue life under dry and lubricated point contact conditions: A numerical study. Tribology International, vol. 152, p. 106584, D0l:10.1016/j. triboint.2020.106584.

[142]0tero, J., De la Guerra, E., Tanarro, E.C., Río, B. (2017). Friction coefficient in mixed lubrication: A simplified analytical approach for highly loaded non-conformal contacts. Advances in Mechanical Engineering, vol. 9, no. 7, D0I:10.1177/1687814017706266.

[143]Zhu, D., Hu, Y. (2001). A computer program package for the prediction of EHL and mixed lubrication characteristics, friction, subsurface stresses, and flash temperatures based on measured 3-D surface roughness. Tribology Transactions, vol. 44, p. 383-390, D0l:10.1080/10402000108982471.

[144]Castro, J., Seabra, J. (2007) Coefficient of friction in mixed film lubrication: gears versus twin-discs. Proceedings of the Institution of Mechanical Engineers, Part J: Journal of Engineering Tribology, vol. 221, no. 3, p. 399-411, DOI:10.1243/13506501JET257.

[145]van Beek, A. (2012). Advanced engineering design: Lifetime performance and reliability. TU Delft, The Netherlands.
[146]Thompson, M.K. (2007). A multi-scale iterative approach for finite element modeling of thermal contact resistance. $\mathrm{PhD}$ Thesis. Massachusetts Institute of Technology, Massachusetts, DOI:10.1115/MNHT2008-52385.

[147] Nayak, P.R. (1971). Random process model of rough surfaces. Journal of Lubrication Technology, vol. 93, no. 3, p. 398-407, D0I:10.1115/1.3451608.

[148] Kartini, Saputra, E., Ismail, R., Jamari, J., Bayuseno, A.P. (2016). Analysis of the contact area of smooth and rough surfaces in contact with sphere indenter using finite element method. MATEC Web of Conferences, vol. 58, p. 04007, DOl:10.1051/matecconf/20165804007.

[149]Wu, J.-J. (2000). Simulation of rough surfaces with FFT. Tribology International, vol. 33, no. 1, p. 47-58, D0l:10.1016/ S0301-679X(00)00016-5.

[150]Hu, Y.Z., Tonder, K. (1992). Simulation of 3-D random surface by 2-D digital filter and Fourier analysis. International Journal of Machine Tools and Manufacture, vol. 32, no. 1-2, p. 82-90.

[151] Perez-Rafols, F., Almqvist, A. (2019). Generating randomly rough surfaces with given height probability distribution and power spectrum. Tribology International, vol. 131, p. 591-604, DOI:10.1016/j.triboint.2018.11.020.

[152]Pawlus, P.; Reizer, R.; Wieczorowski, M. (2020). A review of methods of random surface topography modeling. Tribology International, vol. 152, p. 106530, D0l:10.1016/j. triboint.2020.106530.

[153]You, S.J., Ehmann, K.F. (1991). Computer synthesis of threedimensional surfaces. Wear, vol. 145, no. 1, p. 29-42, Dol:10.1016/0043-1648(91)90237-0.

[154]Chang, W.R., Etsion, I., Bogy, D.B. (1987). An elasticplastic model for the contact of rough surfaces. Journal of Tribology, vol. 109, p. 257-263.

[155]Zhao, Y., Maietta, D.M., Chang, L. (2000). An asperity microcontact model incorporating the transition from elastic deformation to fully plastic flow. Journal of Tribology, vol. 122, no. 1, p. 86-93, D0I:10.1115/1.555332.

[156] Kogut, L., Etsion, I. (2002). Elastic-plastic contact analysis of a sphere and a rigid flat. Journal of Applied Mechanics, vol. 69, no. 5, p. 657-662, D0I:10.1115/1.1490373.

[157]Jackson, R.L., Green, I. (2005). A finite element study of elasto-plastic hemispherical contact against a rigid flat. Journal of Tribology, vol. 127, no. 2, p. 343-354, DOI:10.1115/1.1866166.

[158]Mishra, T., de Rooij, M., Schipper, D.J. (2021). The effect of asperity geometry on the wear behaviour in sliding of an elliptical asperity. Wear, vol. 470-471, p. 203615 , D0l:10.1016/j.wear.2021.203615.

[159]Zhou, C., Wang, H., Wang, H., Hu, B. (2021). Threedimensional asperity model of rough surfaces based on valley-peak ratio of the maximum peak. Meccanica, vol. 56, p. 711-730, D0l:10.1007/s11012-021-01309-3.

[160]Zhu, L., Chen, J., Sun, Y. (2021). On the approximating criteria of parabolic asperities for measured surface profiles. American Institute of Physics Advances, vol. 11, p. 035134 , DOI:10.1063/5.0046579.

[161] Tsao, Y.H., Tong, K.N. (1975). A model for mixed lubrication. American Society of Lubrication Engineers Transactions, vol. 18, no. 2, p. 90-96, DOI:1080/05698197508982750. 
[162] Szczerek M., Wisniewski M. (2001). Theories of mixed friction. Szczerek M., Wisniewski M. (eds). Tribolgy and Tribotechnics. ITeE. Radom.

[163] Polyacetal (POM) Plastem, (2021). from http://www.plastem. pl/en/offer/plastics/polyacetal-pom/, accessed on 2021-1231.

[164]Bowden, F.P., Tabor, D. (1950) \& (1964). The Friction and Lubrication of Solids, Part I (1950) \& Part II (1964). Oxford Clarendon Press, Oxford.

[165]Patir, N., Cheng, H.S. (1978). An average flow model for determining effects of three-dimensional roughness on partial hydrodynamic lubrication. Journal of Lubrication Technology, vol. 100, no. 1, p. 12-17, D0l:10.1115/1.3453103.

[166]Wilson, W., Marsault, N. (1998). Partial hydrodynamic lubrication with large fractional contact areas. Journal of Tribology, vol. 120, no. 1, p. 16-20, Dol:10.1115/1.2834180.

[167] Kakoi, K. (2021). Formulation to calculate isothermal, nonnewtonian elastohydrodynamic lubrication problems using a pressure gradient coordinate system, and its verification by an experimental grease. Lubricants, vol. 9, no. 5, p. 56, DOI:10.3390/lubricants9050056.

[168] Radulescu, A.V., Radulescu, I. (2006). Rheological models for lithium and calcium greases. Mechanica, vol. 59, no. 3, p. 6770.

[169]Clarke, S., Bell, M.A. (2008). Modelling of friction in a ball joint in mixed lubrication. Proceedings of the Institution of Mechanical Engineers, Part C: Journal of Mechanical Engineering Science, vol. 222, p. 267-275, DOI:10.1243/09544062JMES437.
[170]Walicki, E., Walicka, A. (2000). Mathematical modelling of some biological bearings. Smart Materials and Structures, vol. 9, no. 3, p. 280-283, Dol:10.1088/0964-1726/9/3/305.

[171] Pacejka, H.B., Bakker, E. (1993). The Magic Formula Tyre Model. Pacejka H.B. (eds). Tyre Models For Vehicle Dynamics Analysis, 1st ed., CRC Press, p. 1-18, DOI:10.1080/00423119208969994.

[172]Rega, G., Wang, X., Shi, S., (2015). Analysis of vehicle steering and driving bifurcation characteristics. Mathematical Problems in Engineering, vol. 2015, p. 847258, DOI:10.1155/2015/847258.

[173] Nguyen, V. (2005). Vehicle handling, stability, and bifurcation analysis for nonlinear vehicle models. PhD thesis. College Park, University of Maryland, Maryland.

[174] Sahin, Y., Pauw, J., Sukumaran, J., de Baets, P. (2015). Sliding Friction and Wear of Polyoxymethylene Polymer. Synergy International Conferences - Engineering, Agriculture and Green Industry Innovation.

[175] Mergler, Y.J., Schaake, R.P., Huis in't Veld, A.J. (2004). Material transfer of POM in sliding contact. Wear, vol. 256, p. 294-301, DOl:10.1016/S0043-1648(03)00410-1.

[176]Zunda, A., Padgurskas, J., Jankauskas, V., Levinskas, R. (2010). Wear Resistance of Industrial Polymers Under Lubrication with Oils. Scientific Journal of Riga Technical University. Material Science and Applied Chemistry, vol. 21, p. 21-25.

[177] Golchin, A., Simmons, G., Glavatskih, S., Prakash, B. (2013). Tribological behaviour of polymeric materials in water-lubricated contacts. Proceedings of the Institution of Mechanical Engineers, Part J: Journal of Engineering Tribology, vol. 227, no. 8, p. 811-825, Dol:10.1177/1350650113476441. 